\title{
Characteristics of cloud liquid water path from SEVIRI onboard the Meteosat Second Generation 2 satellite for several cloud types
}

\author{
A. Kniffka ${ }^{1}$, M. Stengel ${ }^{1}$, M. Lockhoff ${ }^{1}$, R. Bennartz ${ }^{2}$, and R. Hollmann ${ }^{1}$ \\ ${ }^{1}$ Satellite-based Climate Monitoring, Deutscher Wetterdienst, Strahlenbergerstr. 13, 63067 Offenbach, Germany \\ ${ }^{2}$ University of Wisconsin - Madison, 1225 W. Dayton St., Madison, WI 53706, USA
}

Correspondence to: A. Kniffka (anke.kniffka@dwd.de)

Received: 3 July 2013 - Published in Atmos. Meas. Tech. Discuss.: 2 October 2013

Revised: 12 February 2014 - Accepted: 13 February 2014 - Published: 4 April 2014

\begin{abstract}
In this study the temporal and spatial characteristics of the liquid water path (LWP) of low, middle and high level clouds are analysed using space-based observations from the Spinning Enhanced Visible and Infrared Imager (SEVIRI) instrument onboard the Meteosat Second Generation 2 (MSG 2) satellite. Both geophysical quantities are part of the CLAAS (CLoud property dAtAset using SEVIRI) data set and are generated by EUMETSAT's Satellite Application Facility on Climate Monitoring (CM SAF). In this article we focus on the statistical properties of LWP, retrieved during daylight conditions, associated with individual cloud types. We analysed the intrinsic variability of LWP, that is, the variability in only cloudy regions and the variations driven by cloud amount. The relative amplitude of the intrinsic diurnal cycle exceeded the cloud amount driven amplitude in our analysed cases. Our results reveal that each cloud type possesses a characteristic intrinsic LWP distribution. These frequency distributions are constant with time in the entire SEVIRI field of view, but vary for smaller regions like Central Europe. Generally the average LWP is higher over land than over sea; in the case of low clouds this amounts to $15-27 \%$ in 2009. The variance of the frequency distributions is enhanced as well. Also, the average diurnal cycle of LWP is related to cloud type with the most pronounced relative diurnal variations being detected for low and middle level clouds. Maps of the relative amplitude and the local time of maximum LWP show the variation throughout the SEVIRI field of view.
\end{abstract}

\section{Introduction}

An essential parameter for monitoring climate variability is the large-scale view of the cloud-field distribution. Clouds influence strongly the energy budget and water cycle of the Earth and have therefore a major impact on the atmospheric state at shorter time periods as well at climate relevant timescales. Due to their complexity in both formation mechanisms as well as spatial and temporal variability, the knowledge about many cloud aspects is limited. In a recent comparison of general circulation models the consistency with observations differed strongly among the models. In particular, low clouds accounted for much of the climate sensitivity in the considered models (Williams and Webb, 2009). Bony and Dufresne (2005) studied in detail the tropical cloud evolution in general circulation models and suggest that the representation of marine-boundary-layer clouds is the main source of uncertainty in tropical cloud feedbacks simulated by the models. Satellite data, amongst others, can help to improve our understanding by serving as input for climate models or numerical weather prediction models. Jiang et al. (2012) intercompared 19 climate models in the Cloud Model Intercomparison Project (CMIP). They documented the improvement of the description of column-integrated cloud amount in more than half of the models from Phase 3 to Phase 5 of the project. Chlond et al. (2004) modelled the liquid water path (LWP) of marine clouds with large eddy simulation and single column models and stated that clouds remain the largest uncertainty for assessing the impact of anthropogenic influence on climate change. Naturally, the complexity of clouds is not only a challenge for modelling but also for the retrieval of cloud properties via radiance measurements 
from satellites. The comparability of several satellite-derived cloud data sets is explored, for example, in the Global Energy and Water Cycle Experiment (see Stubenrauch et al., 2009). Retrieval algorithms for cloud properties detection from passive imager instruments on-board the polar and geostationary satellites AVHRR, MODIS and SEVIRI are compared in the framework of Eumetsat's CREW (Cloud Retrieval Evaluation Workshop) project (Roebeling et al., 2012). The measured brightness temperatures and reflectance of clouds depend strongly upon their macro- and microphysical characteristics such as cloud amount and cloud top height; the droplet size distribution; cloud texture; and the thermodynamic phase. They are also affected by the atmospheric conditions and by the respective sun and satellite positions. Having a good knowledge of these conditions and positions allows the retrieval of cloud properties from the remaining signal.

The diurnal or daytime cycle of satellite-derived LWP has been well documented in several studies (Wood et al., 2002; O'Dell et al., 2008; Painemal et al., 2012), mainly for specific regions such as the west coast of South America (Painemal et al., 2012). The good temporal resolution and high spatial coverage of measurements from geostationary satellites qualifies the derived cloud properties even more to be analysed concerning their diurnal variability. Early LWP studies with GOES 9 measurements were carried out by Greenwald and Christopher (1999); an analysis of LWP diurnal cycle in marine-boundary-layer clouds with respect to aerosol load was undertaken by Chellappan (2011). Comparisons to regional climate model simulations of SEVIRI-derived cloud amount and LWP can be found in Roebeling and Van Meijgaard (2009) as well as Pfeifroth et al. (2012). Roebeling and Van Meijgaard (2009) proved the suitability of SEVIRIderived cloud amount and LWP for climate model evaluation. In our study, we go beyond the simplified type of cloud approach and analyse and discuss the relationship between cloud type and liquid water path as they are categorised by CM SAF (EUMETSAT's Satellite Application Facility on Climate Monitoring). Both variables are derived from the Spinning Enhanced Visible and Infrared Imager (SEVIRI) onboard the Meteosat Second Generation 2 (MSG 2) satellite. Characteristic features of LWP concerning its distribution and diurnal cycle for the individual cloud types are explored. The results of the one year time-frame are put into context with the University of Wisconsin (UWisc) cloud liquid water path climatology derived from 18 years of passive microwave observations (see O'Dell et al., 2008). The general features of LWP, for example, frequency distribution, average value and diurnal cycle are specified to serve as characteristic measures in atmospheric numerical modelling. More specifically, they can be used to conduct process studies, assist in the evaluation of microphysical measurement experiments such as the airborne probing of clouds and serve as input for cloud generators and radiative transfer studies on a wide range of spatial scales. The temporal resolution of MSG 2 permits assessing the temporal evolution of cloud systems in cloud resolving models and facilitates model evaluation studies such as those undertaken in Hannay et al. (2009), Brunke et al. (2010), or the other above mentioned articles.

The article is structured as follows: in Sect. 2 the methods of the LWP and CTY (cloud type) retrieval from SEVIRI measurements are described, Sect. 3 contains the analysis of LWP with respect to CTY, where the statistical properties are considered first, followed by a subsection on liquid water in high opaque clouds. The analysis is completed with a consideration of LWP diurnal cycle for several regions and a comparison with the climatology of microwave-based LWP observations (O'Dell et al., 2008). Also the seasonal variations for the considered year are presented in a subsection. In Sect. 4 the results are discussed taking into account the limitations of a geostationary imager.

\section{Generation of LWP and CTY from SEVIRI measurements}

In this study, non-averaged data of LWP and CTY derived from SEVIRI measurements form the basis for the data set. Both parameters are part of the CLAAS (CLoud property dAtAset Using SEVIRI) data set by CM SAF (Schulz et al., 2009) that includes cloud micro- and macrophysical properties as well as surface albedo and spans the time period 2004-2011. The radiances were measured with the passive optical imaging radiometer SEVIRI (Schmetz et al., 2002). It is equipped with 12 spectral channels at visible and infrared wavebands. SEVIRI is mounted on the geostationary MSG satellites, where MSG 1 and MSG 2 measurements were projected so that the subsatellite point appears to be at $0^{\circ}$ latitude and longitude while they are in operational mode. The horizontal resolution of a SEVIRI image is $3 \mathrm{~km} \times 3 \mathrm{~km}$ at nadir. Hourly radiances from the level 1.5 EUMETSAT (2010) data were used as input. This was the reprocessed version with updated radiance definitions (EUMETSAT, 2007). More details can be found in Stengel et al. (2013) and in Kniffka et al. (2013a). The Level 1.5 radiances were additionally calibrated against MODIS Aqua (Moderate Resolution Imaging Spectroradiometer on Aqua) (see Meirink et al., 2013). The input radiance fields were processed with the CM SAF algorithms but have not undergone temporal and spatial averaging at that stage. The months considered were January, April, July and October 2009, thus giving one representative month per season, in hourly resolution.

Macro- and microphysical parameters were created with two independently developed algorithms. The CPP v3.9 algorithm of CM SAF, developed at KNMI (Royal Netherlands Meteorological Institute), was employed to retrieve the cloud liquid water path (Roebeling et al., 2006), while cloud mask and cloud type are derived with the Satellite Application Facility on Support to Nowcasting \& Very Short 
Range Forecasting (NWC SAF) algorithm v2010 by Météo France (Derrien, 2010; Derrien and Le Gléau, 2005), see also Sect. 2.2 for details about both retrievals.

\subsection{Cloud type classification}

Both macrophysical parameters, CTY and LWP, need the cloud mask as input. The cloud mask is prepared with the NWC SAF algorithm v2010 (Derrien and Le Gléau, 2005, 2010), which is comprised of a sequence of threshold tests for different combinations of SEVIRI channels at both visible and infrared wavelengths. The algorithm produces 15 cloud classes and from these classes five more general types are derived for the CLAAS data set. CM SAF categorises the cloudy pixels into the classes: low, medium, high opaque, high semitransparent and fractional, which means that the cloud types are determined from a radiation-based point of view. In general, a threshold technique is applied with a sequence of various tests using the following channels: $1.6 \mu \mathrm{m}$, $3.7 \mu \mathrm{m}, 3.9 \mu \mathrm{m}, 8.7 \mu \mathrm{m}, 11 \mu \mathrm{m}$ and $12 \mu \mathrm{m}$. For individual pixels, the employed test sequence depends on the illumination conditions, which can be twilight, daylight or night-time. Also the geographical location, the viewing geometry, the water vapour content and a coarse atmospheric structure are taken into account, where the latter two are both described by numerical weather prediction data. Vertical profiles of temperature, humidity and water vapour content from ERA interim were also used. ERA interim is a global reanalysis and is produced within the ERA reanalysis project of the European Centre for Medium-Range Weather Forecasts (Dee et al., 2011). As a first step, pixels with semitransparent or fractional clouds are identified. After that, the low, middle and high cloud classification is performed by using a threshold for the brightness temperature of the $10.8 \mu \mathrm{m}$ channel that is related to the cloud top height. ERA interim analysis temperatures at several pressure levels are used to compute the thresholds that allow the separation of very low clouds from low clouds, low from medium-high clouds and so on. From statistical analysis of the cloud top pressure, which is assigned afterwards, five cloud top pressure ranges for the different cloud types resulted (see Table 1). For cloud type, pressure and cloud liquid water path the NWC SAF cloud mask is used as input. A type is only derived for a pixel that was masked as completely cloudy. Mainly cloud-free pixels with inherent sub-pixel cloudiness are ascribed to the fractional cloud class without further testing.

The 15 cloud types that originally result from the algorithm (see Table 2) are grouped by CM SAF into five more general classes which are low clouds, middle level clouds, high opaque, high semitransparent and fractional clouds.

Usually the latter step is done during the spatial and temporal averaging procedure, but since in this study the non-averaged (level 2) data were analysed, the reclassification was done directly after the CTY-algorithm. With the
Table 1. Cloud types of CM SAF CTY parameter and corresponding pressure levels (see Derrien 2010).

\begin{tabular}{ll}
\hline Cloud type & $p$ \\
\hline Very low opaque clouds & $p>800 \mathrm{hPa}$ \\
Low opaque clouds & $650 \mathrm{hPa}<p \leq 800 \mathrm{hPa}$ \\
Medium opaque clouds & $450 \mathrm{hPa}<p \leq 650 \mathrm{hPa}$ \\
High opaque clouds & $300 \mathrm{hPa}<p \leq 450 \mathrm{hPa}$ \\
Very high opaque clouds & $p \leq 300 \mathrm{hPa}$ \\
\hline
\end{tabular}

algorithms one cloud layer can be detected, in case of multilayer clouds only the top layer type will be retrieved.

Evaluation of the cloud type product is carried out by CM SAF as described in Hollmann (2011). Here the cloud type product from two sensors, SEVIRI and AVHRR (Advanced Very High Resolution Radiometer) is compared. Since the cloud type classes are not completely equal for the two sensors, two artificial classes are generated, to reduce the data to the least common denominator: high clouds and cirrus clouds. The time series of AVHRR and SEVIRI-based products resemble each other closely in case of high clouds, though it has to be noted that even with the generation of the artificial classes the two products are not completely based on the same conditions. Both products are also compared against MODIS which shows 10-20\% smaller values (\% is to be understood in absolute units, i.e. $10 \%$ cloud fraction of type $x$ ). This could be expected, because MODIS "High clouds IR" category defines all clouds detected above $400 \mathrm{hPa}$, while for the corresponding CM SAF products the reference level is $500 \mathrm{hPa}$. Also the cirrus clouds class is compared against MODIS, for the SEVIRI product differences between 10-20\% occur, where MODIS gives a higher fraction. These can partly be explained by the differences in the reference thresholds for MODIS and SEVIRI, leading to more observed clouds with the MODIS instrument, but naturally high and thin clouds can be more reliably detected with a spectrally and spatially higher resolved instrument.

For a typical CTY field with liquid water and ice pixels on the SEVIRI field of view, also called SEVIRI disc, see Fig. 1 on the left hand side. In this snapshot all cloud types are present, at the same time low and high opaque clouds dominate most of the cloudy regions. The corresponding LWP values are displayed on the right-hand side. The LWP field covers a smaller region due to the restriction of both, the viewing zenith angle and the solar zenith angle being smaller than $72^{\circ}$ (Stengel et al., 2013). Also note that particularly in the tropical regions the cloudy pixels are often icy on top, in this figure they are not displayed because of the restriction to liquid only pixels. Highest values for LWP can be found mainly in cloud bands with high opaque clouds, but also low and middle level clouds can be associated by the retrieval algorithms with high LWP values, for example, Central Europe. 
Table 2. Transfer table from sophisticated NWC SAF msgv2012 cloud classes to the general cloud types provided by CM SAF (see Derrien 2010).

\begin{tabular}{ll}
\hline Cloud type & Cloud class \\
\hline Low clouds & $\begin{array}{l}\text { very low and cumuliform clouds } \\
\text { very low and stratiform clouds } \\
\text { low and cumuliform clouds } \\
\text { low and stratiform clouds }\end{array}$ \\
\hline Middle level clouds & $\begin{array}{l}\text { medium and cumuliform clouds } \\
\text { medium and stratiform clouds }\end{array}$ \\
\hline High opaque clouds & $\begin{array}{l}\text { high opaque and cumuliform clouds } \\
\text { high opaque and stratiform clouds } \\
\text { very high opaque and cumuliform clouds } \\
\text { very high opaque and stratiform clouds }\end{array}$ \\
\hline High semitransparent clouds & $\begin{array}{l}\text { high semitransparent thin clouds } \\
\text { high semitransparent meanly thick clouds } \\
\text { high semitransparent thick clouds } \\
\text { high semitransparent above low or } \\
\text { medium clouds }\end{array}$ \\
\hline Fractional clouds & fractional clouds \\
\hline
\end{tabular}

\subsection{Cloud liquid water path derivation}

For consistency reasons, CPP v3.9 makes use of the cloud mask processed beforehand. In principle, the retrieval method (Roebeling et al., 2006) relies on the assumption that cloud reflectance and so SEVIRI's visible channels are mainly influenced by the cloud's optical thickness, whereas changes in the near infrared depend on the effective radius $\left(r_{\text {eff }}\right)$ of the cloud droplets. The $0.6 \mu \mathrm{m}$ channel and the $1.6 \mu \mathrm{m}$ channel proved to deliver the most accurate results (Roebeling et al., 2006). COT and $r_{\text {eff }}$ are determined by comparing simultaneously the measured reflectances for the 2 channels with reflectances in look-up tables for various values of COT and $r_{\text {eff. }}$. The look-up tables were generated with the doubling-adding KNMI (DAK) radiative transfer model, which makes use of a doubling-adding method (De Haan et al., 1987; Stammes, 2001). In the model, clouds are assumed to be plane parallel and horizontally homogeneous and they are embedded in a vertically stratified medium allowing for Rayleigh scattering. Surface albedo is assumed to have a constant value of 0.1 over land and 0.05 over ocean for $0.6 \mu \mathrm{m}$ as well as 1.5 and 0.05 for the $1.6 \mu \mathrm{m}$ channel. The droplets themselves are assumed to be spheres with effective radii between 1 and $24 \mu \mathrm{m}$ and an effective variance of 0.15 in their gamma type distribution. The cloud liquid water path is finally retrieved via the relation (Stephens, 1978):

$\mathrm{LWP}=\frac{2}{3} \mathrm{COT} r_{\mathrm{eff}} \rho$

with $\rho$ being the density of liquid water. The retrieved particle size values are unreliable for optically thin clouds and so for clouds with cloud optical thickness COT $<8$, the climatological value $8 \mu \mathrm{m}$ is used, which is similar to values used by Rossow and Schiffer (1999).

Roebeling et al. (2008) validated the retrieved LWP values with CloudNET data from two measurement sites: Chilbolton and Palaiseau. At the two sites, measurements were taken with microwave radiometers (MWR). One year of MWR-retrieved values were compared to the SEVIRI LWP values, retrieved with the algorithm outlined above. The derived accuracy is variable and depends on a number of factors, mainly viewing geometry, collocation uncertainties and the inhomogeneity of clouds. For summer months, daily and monthly derived LWP values agreed within $5 \mathrm{~g} \mathrm{~m}^{-2}$, corresponding to a relative accuracy of $10 \%$. In winter, the accuracy was found to be $10 \mathrm{~g} \mathrm{~m}^{-2}$, which was caused by the unfavourable viewing geometry and the smaller amount of data available. The diurnal variations of SEVIRI-derived LWP did not differ by more than $5 \mathrm{~g} \mathrm{~m}^{-2}$ from the MWRmeasurements.

The CLAAS data set itself has undergone a careful validation process, whose results are documented in the validation report of CM SAF (Kniffka et al., 2013b). The nonaveraged cloud phase was validated on a pixel-by-pixel basis with CALIOP on CALIPSO (Cloud-Aerosol Lidar with Orthogonal Polarization on Cloud-Aerosol Lidar and Infrared Pathfinder Satellite Observations). LWP was also compared against MODIS on a nonaveraged pixel-by-pixel basis; LWP and $\mathrm{CPH}$ (cloud phase) were compared using the complete time series of monthly mean values.

The 8 year cloud-phase time series of CLAAS was compared to the MODIS Optical and the MODIS Infrared data set (Meirink et al., 2014), it generally agrees with both, but 

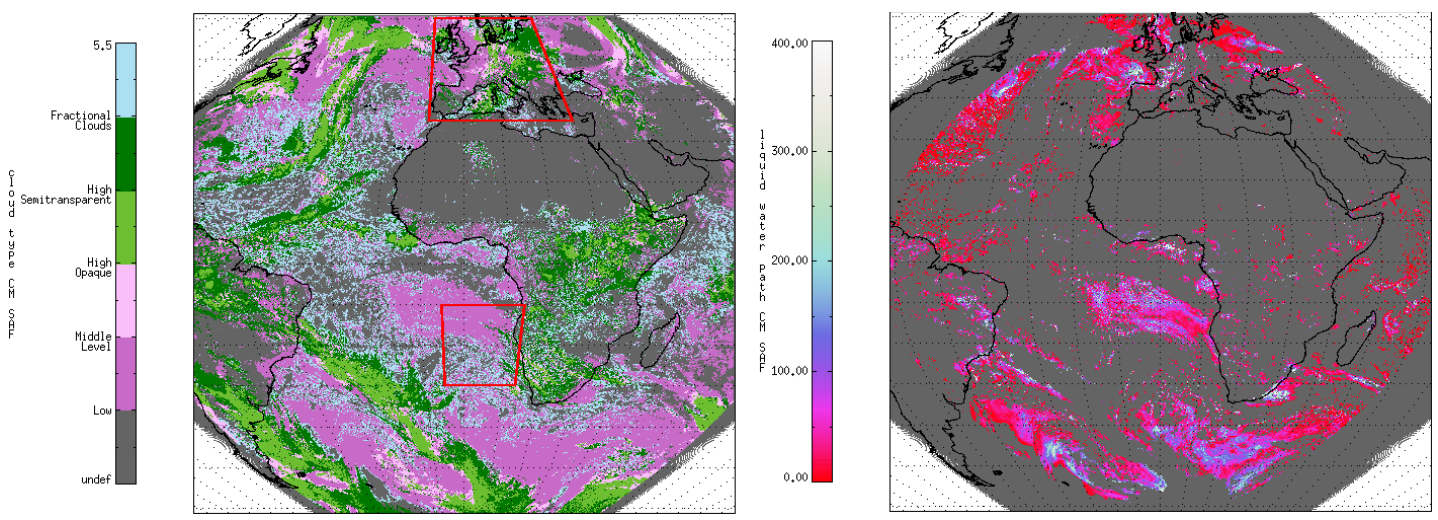

Fig. 1. Left: cloud type for liquid and ice pixel on full SEVIRI disc with horizontal resolution $3 \mathrm{~km} \times 3 \mathrm{~km}$ at subsatellite point, the red squares depict the two regions of interest, right: liquid water path; both at 11:45 UTC, 10 October 2009.

best with the MODIS-IR product. When studying the spatial patterns, differences in the liquid cloud fraction over the tropical land and the liquid cloud fraction in the Sahara and at high solar zenith angles can be noticed. In CLAAS, the cloud fraction over the tropical land is larger than in MODIS but smaller at high solar zenith angles and in the Sahara, where the liquid fraction is inherently uncertain due to the generally small cloud fraction.

The liquid water path time series of CLAAS and MODIS are in very good agreement; in particular the seasonal cycle is nearly identical. Also the spatial patterns that are produced by MODIS and SEVIRI are in good agreement, though differences can be found in regions with strongly broken cloud cover (e.g. the South Atlantic trade cumulus region), where the algorithms have different treatments of clear-sky restoral and the pixel resolution has a great effect. CPH, LWP and cloud fractional cover (CFC) including CTY meet the requirements for a qualified data set of the CM SAF project (Kniffka et al., 2013b).

\section{Analysis}

This analysis is based on level 2 data sets of CTY and LWP, with CPH as auxiliary data. Four months of 2009 were analysed instead of averaging over a complete year in order to highlight the effect of the individual seasons. In the following, only those pixels that were marked as filled with liquid water were considered; ice or mixed phase pixels were excluded from the discussion. The analysis was restricted to liquid cases since the two branches of liquid and ice retrieval in the CPP algorithm are not comparable. Ice crystals have a larger variety of shapes, for example, hexagons and clustered pieces in various forms, as opposed to spherical liquid droplets. Therefore more assumptions have to be made concerning the shape of the particles in the retrieval of ice water content.
All cases refer to the intrinsic variability of LWP. This means we have only taken into account liquid-filled pixels to eliminate the effect of changes in CFC in, for example, the diurnal cycle of LWP. The comparison with the LWP climatology of O'Dell et al. (2008) is an exception for the sake of comparability. Here we also took the chance to demonstrate CFC and LWP diurnal fluctuations for a predefined region.

In the following, 4 different cases are analysed: first a general full disc analysis including cloud class, land and water distinction for four months in 2009, second a European analysis heterogenous for land and water pixels, third the low cloud deck off the coast of Namibia and Angola analysis with oceanic low clouds including a comparison to a cloud water path climatology derived from passive microwave observations (O'Dell et al., 2008) and fourth a comparison of LWP diurnal cycles for four months and all cloud types on the Northern Hemisphere.

\subsection{General characteristics of distributions and statistical properties}

One objective of the present study is to explore the potential for parameterisation of LWP in relation to CTY suitable for process studies or model evaluation and testing. From each pair of LWP and CTY fields frequency distributions of LWP were determined for the individual cloud types, where the pixels were sorted with respect to local time. It was found that the shape of the frequency distributions themselves remained constant with time, when larger areas are considered, e.g. half of the SEVIRI field of view. Bugliaro et al. (2011) evaluated the cloud property retrievals used by CM SAF with simulated satellite radiances based on the output of the COSMO-EU weather model. It was found that CM SAF's algorithms are capable of reproducing the predetermined LWP distribution regarding the form (modal classes and skewness), with a slight overestimation of the histogram peak location and an underestimation of the peak number of occurrences. 

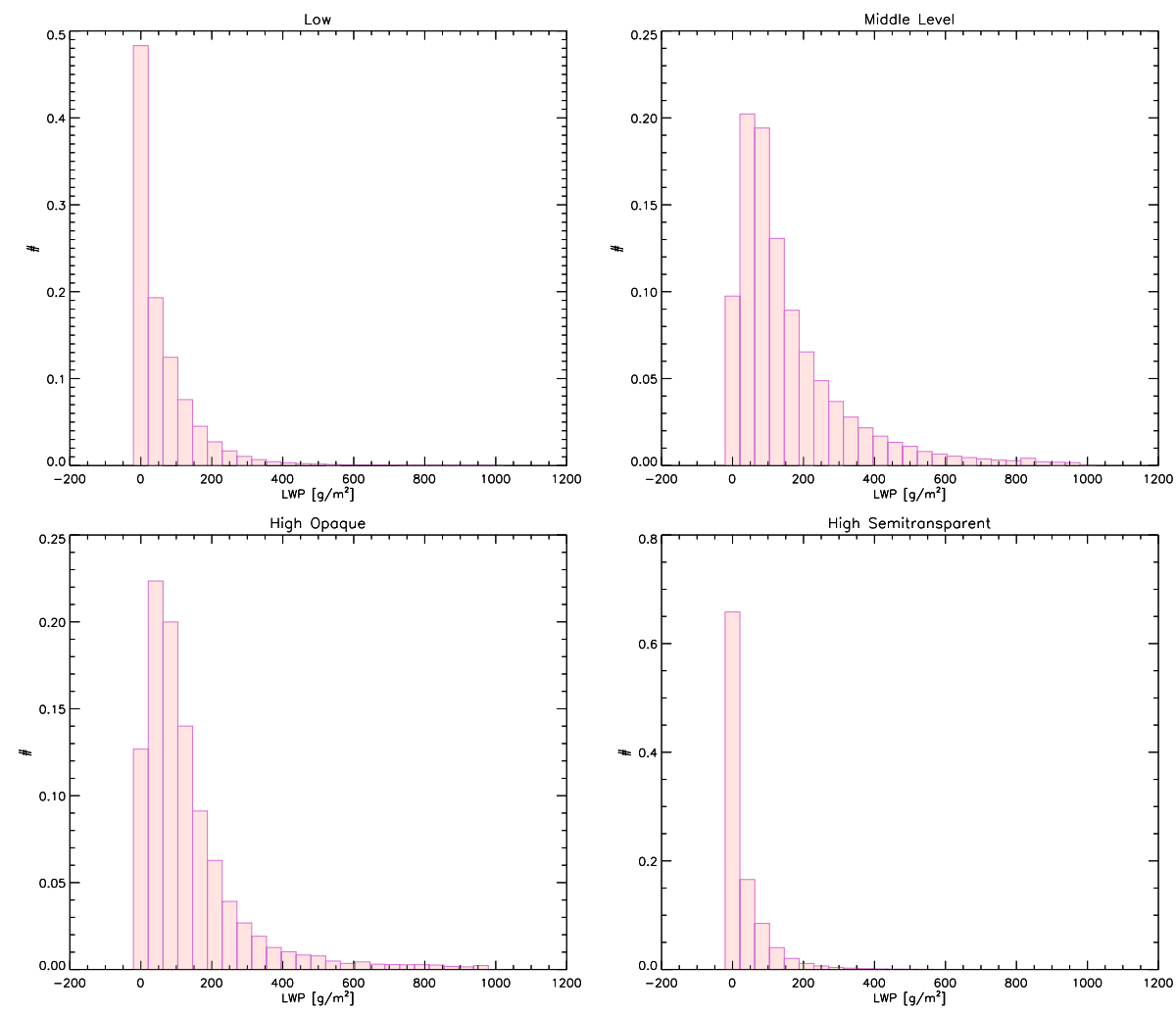

Fig. 2. Frequency distribution of LWP for 4 cloud types, average from the SEVIRI disc for 7 October 2009. Upper left: low clouds; upper right: middle level; lower left: high opaque; lower right: high semitransparent.

The distributions for all points in time and all cloud types are unimodal and positively skewed. With these constant properties it is possible to characterise the liquid part of a cloud type as having a certain distribution. For a mathematical description either a log-normal distribution or a gamma type distribution has to be chosen. The non-zero skewness forbids description with the help of a Gaussian distribution. This corresponds to the findings of de la Torre Juárez et al. (2011) who derived fitting functions for the probability distributions of LWP amongst other cloud properties retrieved from MODIS-Aqua. In their work, the best fit was found to be either a log-normal or gamma type distribution, depending on the considered spatial scale. Unlike in Considine et al. (1997), who proposed Gaussian distributions in case of very large cloud fractions close to $100 \%$, a Gaussian distribution was never found to produce the best fit. The gamma type distribution has also been observed from shipbased as well and airborne measurements (McBride et al., 2012).

In general, the CLAAS distributions of the LWP can be characterised as such (Fig. 2): low clouds show on average a rather narrow highly peaked distribution with small LWPs of approximately $67.2-86.2 \mathrm{~g} \mathrm{~m}^{-2}$. The averaged variance ranges from 21.9 to $29.7 \mathrm{~g} \mathrm{~m}^{-2}$.
Middle level clouds possess a larger spectrum of LWP, the average values are between $153.8 \mathrm{~g} \mathrm{~m}^{-2}$ in July and $174.8 \mathrm{~g} \mathrm{~m}^{-2}$ in October while the variance lies between $51.5 \mathrm{~g} \mathrm{~m}^{-2}$ in April and $58.1 \mathrm{~g} \mathrm{~m}^{-2}$ in January.

The distributions with highest absolute values can be found in the high opaque cloud class, for which the distribution is not as broad as for middle level clouds. For these classes, the average values range from $148.8 \mathrm{~g} \mathrm{~m}^{-2}$ in January up to $187.3 \mathrm{~g} \mathrm{~m}^{-2}$ in April. The variance changes between $50.3 \mathrm{~g} \mathrm{~m}^{-2}$ in October and $59.2 \mathrm{~g} \mathrm{~m}^{-2}$ in July. High semi-transparent clouds again have smaller average values compared to the high opaque class $\left(34.4 \mathrm{~g} \mathrm{~m}^{-2}\right.$ in April $43.9 \mathrm{~g} \mathrm{~m}^{-2}$ in October) and the most narrow distributions of all (variance: $11.0 \mathrm{~g} \mathrm{~m}^{-2}$ in April $-16.0 \mathrm{~g} \mathrm{~m}^{-2}$ in January). More figures on averages and variances for the complete MSG disc as well as a subset for Europe can be found in Table 4.

As a next step, let us consider specified regions. A distinction between land and water pixels leads to the following observations: distributions appear broader for land pixels than for water pixel. This means that the variance is greater and more high LWP values are measured. On average LWP is higher over land than over sea: for example low clouds show the following behaviour: in January $98.8 \mathrm{~g} \mathrm{~m}^{-2}$ over land compared to $84.0 \mathrm{~g} \mathrm{~m}^{-2}$ over sea; April: $78.4 \mathrm{~g} \mathrm{~m}^{-2}$ 

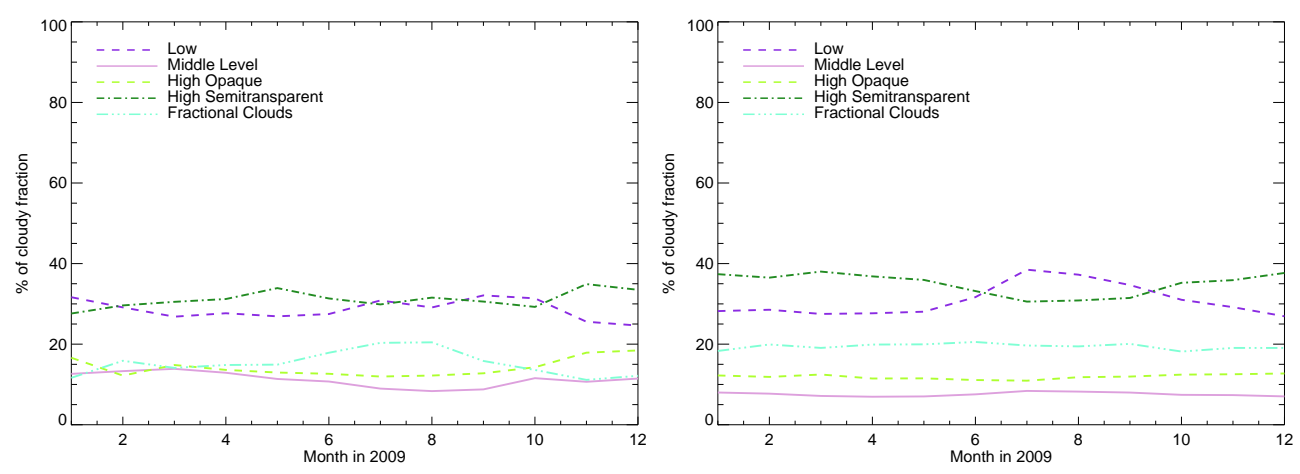

Fig. 3. Averaged proportion of cloud types from the cloudy fraction in 2009 based on monthly mean data; left: Europe; right: SEVIRI disc.

and $65.4 \mathrm{~g} \mathrm{~m}^{-2}$; July: $79.3 \mathrm{~g} \mathrm{~m}^{-2}, 63.4 \mathrm{~g} \mathrm{~m}^{-2}$; and October: $108.6 \mathrm{~g} \mathrm{~m}^{-2}, 79.2 \mathrm{~g} \mathrm{~m}^{-2}$. In Table 3 the average values for all cloud types can be found for the SEVIRI disc, where we also distinguish between land and water pixel. The enhancement of LWP above land is particularly visible for high opaque and middle level clouds. The difference is more pronounced for October and January than for April and July. The peaks in the distributions of high opaque and middle level clouds have lower values, nevertheless the peaks occur approximately in the same LWP bin (not shown in the table). The differences in the distributions of LWP between land and water pixels are likely due to several factors. The albedo of the land surface is much more variable relative to that over the ocean, which will affect convective processes due to solar heating variations. Also the formation of clouds over ocean is influenced by the temperature of the underlying sea current that usually fluctuates more slowly than the surface temperature of land. In addition, the orography has an effect on the atmospheric flow and influences the formation of clouds. On the microphysical scale, aerosol over land is of a different type than that over sea and is also more variable in composition. Additionally the number density concentration is mostly higher over land than over ocean. Over the Atlantic ocean, sea salt dominates together with mineral dust from the Saharan desert (Prospero et al., 1983).

The second focus was placed onto analysing a smaller and more heterogeneous region from the SEVIRI disc, were the surface type (land or water) should vary on a comparably small length scale. Central and Western Europe (between $36^{\circ} \mathrm{N}$ and $60^{\circ} \mathrm{N}$ and $10^{\circ} \mathrm{E}$ and $30^{\circ} \mathrm{W}$ ) were chosen, see Fig. 1. No distinction between land and water pixels was made. The frequency of occurrence of different cloud types in the total cloud coverage is slightly different for Europe than for the full SEVIRI disc. The most striking feature is, that the relations are not constant with time, as can be seen in Fig. 3. In here, the share of the individual cloud types from all cloudy pixels is displayed. On the left hand side the figures for Europe, spatially averaged from the monthly mean data product of CM SAF for the months of 2009, are shown; The full disc data can be found to the right. On the full disc, the proportion of the cloud types - middle level, high opaque and fractional - do not change vigorously during the months of 2009, but in the summer month the low cloud class fraction increases to exceed the high semitransparent one. In Europe, the monthly variation for all cloud types is generally bigger compared to the results for the full SEVIRI disc with an exception: the seasonal variation of low clouds is bigger for the SEVIRI disc. Most noticeable in the European seasonal variation is the increase in fractional clouds during the summer months that is not visible when considering the full disc and the subsequent increase of the high opaque cloud class from September to December. This might indicate that the increase is caused by seasonal changes in the circulation pattern. A shift of the general circulation, such as the meridional movement of the polar front, has an observable effect in this small subset of the SEVIRI disc.

The differences become much more noticeable when considering smaller timescales. For October 2009 daily averages of LWP were calculated from the non-averaged data for the European region. The average is a daylight-only average, that is, where the solar zenith angle is smaller than $72^{\circ}$. The time series for low clouds is displayed in the upper panel in Fig. 4 together with the daily averages.The time series of the daily averages shows a pronounced temporal variation with apparently periodic fluctuations. The repetition period is in the order of several days, which corresponds to the timescale of synoptic features such as cyclones and anticyclones. The auto-correlation function reveals, that the fluctuations solely appear to be periodic, which can be expected for a single month of data within a chaotic dynamic system. It has to be noted that in Fig. 4 all available points in time were plotted, regardless of a possibly low number of observations during sunrise and sunset times due to the varying solar zenith angle. The low values during these times might have a comparably large retrieval error, see below for details. Nevertheless, low LWP values at the respective hours in approximately this region are also simulated with the regional climate model RACMO2, see Roebeling and Van Meijgaard (2009). However, the auto-correlation function is not influenced at larger time lags and an exclusion of the early morning and evening 
Table 3. Average LWP $\left(\mathrm{g} \mathrm{m}^{-2}\right)$ for land and water pixels on the SEVIRI disc for January, April, July and October 2009, only filled pixels were averaged.

\begin{tabular}{lrrrrr}
\hline & Low & Middle level & High opaque & High semi. & Fractional \\
\hline Land & & & & \\
\hline Average values & & & & & \\
Jan & 98.8 & 199.8 & 206.0 & 41.1 & 8.9 \\
Apr & 78.4 & 181.5 & 202.2 & 37.4 & 9.3 \\
Jul & 79.3 & 161.2 & 239.4 & 39.0 & 9.2 \\
Oct & 108.6 & 215.3 & 234.7 & 50.1 & 9.6 \\
Variances & & & & & \\
Jan & 27.5 & 53.7 & 48.7 & 12.0 & 2.9 \\
Apr & 23.6 & 48.7 & 42.3 & 11.7 & 2.7 \\
Jul & 26.2 & 52.4 & 41.7 & 12.6 & 3.0 \\
Oct & 27.4 & 53.6 & 44.8 & 12.5 & 3.0 \\
\hline Water & & & & & \\
\hline Average values & & & & & \\
Jan & 84.0 & 139.4 & 140.3 & 40.6 & 6.7 \\
Apr & 65.4 & 141.6 & 176.5 & 29.5 & 6.3 \\
Jul & 63.4 & 143.4 & 154.3 & 32.5 & 5.8 \\
Oct & 79.2 & 150.8 & 149.4 & 37.2 & 6.3 \\
Variances & & & & & \\
Jan & 27.4 & 52.6 & 48.8 & 14.9 & 2.4 \\
Apr & 19.7 & 46.0 & 44.8 & 8.9 & 1.9 \\
Jul & 19.5 & 49.4 & 40.2 & 11.0 & 1.9 \\
Oct & 22.5 & 47.3 & 42.4 & 10.8 & 2.0 \\
\hline
\end{tabular}

hours does not lead to a better representation of synoptic features.

As can be seen from Table 4, the monthly mean values show enhanced LWP values (on average) for middle level and high opaque clouds. On the contrary, the LWPs of the high semitransparent and the fractional cloud classes are smaller in Europe, compared to the full SEVIRI disc. A typical uncertainty is caused by the viewing geometry of SEVIRI since it is mounted on a geostationary satellite: the cloud amount and also the liquid water path are dependent on the line of sight through the atmosphere, and so the uncertainty increases towards the rims of the disc, see the validation report for CLAAS (Kniffka et al., 2013b). Due to the slant line of sight at high viewing angles, gaps between clouds cannot be seen properly, so the detected cloud amount will be too high towards the rims of the SEVIRI disc. The LWP retrieval is also affected, but not as systematical as cloud amount, because LWP depends on the type of cloud, particularly its vertical and horizontal structure. For a study analysing the dependence of COT retrieval on the viewing angle of MODIS see Varnái and Marshak (2007).

The heterogeneity of clouds has multiple effects on the retrieval accuracy of cloud properties. For SEVIRI's pixel size, two kinds of error are relevant: the plane-parallel bias and the shadowing-illumination error. Schutgens and Roebeling (2009) state, that the shadowing-illumination
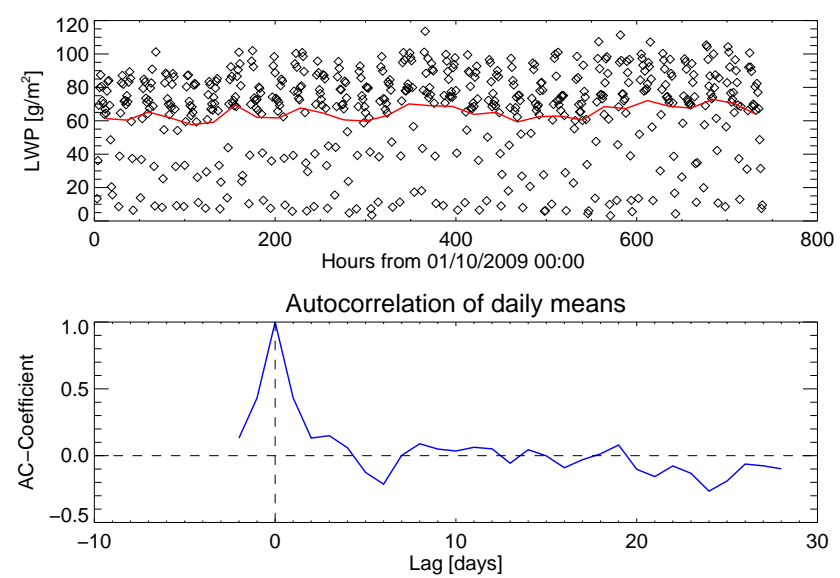

Fig. 4. Upper panel: time series of LWP for low clouds in Europe, 10/2009, diamonds depict spatial averages for Europe of the individual time slots, i.e. one diamond per hour; the red line shows the daily averages of the respective data points; lower panel: autocorrelation function of daily averaged data.

error dominates at shorter spatial scales about $1 \mathrm{~km}$. So the retrieval of LWP for SEVIRI is mainly affected by the planeparallel bias. The plane-parallel problem, which arises when neglecting the varying spatial structure of a cloud within a pixel was widely investigated by many groups. In general, 
Table 4. Average LWP $\left(\mathrm{g} \mathrm{m}^{-2}\right)$ for Europe and SEVIRI disc for January, April, July and October 2009 based on level 2 data, only cloudy pixels were averaged.

\begin{tabular}{lccccc}
\hline & Low & Middle level & High opaque & High semi. & Fractional \\
\hline Europe & & & & \\
\hline Average values & & & & & \\
Jan & 89.0 & 189.8 & 176.6 & 50.4 & 6.8 \\
Apr & 68.0 & 161.6 & 350.1 & 33.5 & 5.6 \\
Jul & 74.6 & 174.7 & 220.6 & 29.5 & 5.0 \\
Oct & 86.7 & 212.5 & 229.1 & 34.9 & 5.8 \\
Variances & & & & \\
Jan & 6.1 & 12.0 & 12.9 & 3.4 & 0.4 \\
Apr & 7.0 & 16.9 & 20.4 & 3.8 & 0.6 \\
Jul & 8.7 & 20.2 & 14.8 & 3.6 & 0.6 \\
Oct & 7.0 & 15.4 & 15.4 & 3.1 & 0.5 \\
\hline SEVIRI disc & & & & & \\
\hline Average values & & & & & \\
Jan & 86.2 & 155.5 & 148.8 & 43.5 & 7.3 \\
Apr & 67.7 & 162.8 & 187.3 & 34.4 & 6.9 \\
Jul & 67.2 & 153.8 & 172.1 & 36.9 & 6.5 \\
Oct & 82.5 & 174.8 & 166.2 & 43.9 & 7.1 \\
Variances & & & & & \\
Jan & 29.7 & 58.1 & 55.3 & 16.0 & 2.7 \\
Apr & 21.9 & 51.5 & 53.0 & 11.0 & 2.2 \\
Jul & 22.7 & 54.8 & 59.2 & 13.0 & 2.3 \\
Oct & 24.8 & 53.9 & 50.3 & 12.5 & 2.4 \\
\hline
\end{tabular}

most studies conclude, that the plane-parallel bias causes an underestimation of COT, which in turn causes an underestimation of LWP. At the same time, the effective radius is often overestimated. Both effects tend to compensate each other when deriving LWP. But the magnitude of the effect depends strongly on the geometric formation of the cloud fields and the viewing conditions (see Marshak et al., 2006; Iwabuchi and Hayasaka, 2002; Barker et al., 1999). Therefore most studies consider the average effect of a small sample of test cases or have to limit the studies with certain constraints (e.g. Schutgens and Roebeling (2009) limited their study to cloud fields that were at least $25 \mathrm{~km}$ contiguous but not patched fields). Marshak et al. (2006) showed, that the sign of the differences in effective radius and cloud optical thickness retrieval depends on the cloud's structure and the viewing conditions (i.e. mainly the sun zenith angle and can be either positive or negative). The bias varies also with cloud type in terms of heterogeneity (i.e. stratiform or cumulus cloud cover). So an overall estimation of retrieval error cannot be given in this paper, but Schutgens and Roebeling (2009) who originally studied the sources of error when validating a sensor with other measurements, also analysed the influence of the plane-parallel assumption on the LWP retrieval, especially for SEVIRI scenes, and the algorithm used for the derivation of the CLAAS data set. The median of the LWP bias amounted to $-3.3 \mathrm{~g} \mathrm{~m}^{-2}$. Here the authors compared LWP from synthetic 100 m cloud fields to LWP on SEVIRI's pixel size.

The connection between high-semitransparent clouds and liquid water can only be rated as approximate, because of an inconsistency between cloud top temperature (CTT) from the msgv2012 algorithm and the one used for the derivation of the cloud physical properties. In CPP v3.9, the cloud top temperature is derived from the $10.8 \mu \mathrm{m}$ channel where a linear relationship between radiance and CTT is assumed and the infrared emissivity of the cloud (Roebeling et al., 2006). While this performs well in most cases, it leads to greater differences between the two independently derived CTTs in the case of high semitransparent clouds where a more sophisticated method would have to be used to refine the results.

\section{Liquid water in high opaque clouds}

It may seem a little optimistic to show distributions of liquid water for high clouds, for example high opaque clouds. The majority of those clouds are regarded as having a cloud top consisting of ice particles. While this is the case for most cloudy pixels in the analysed scenes, it is not true for all high opaque cloud fields. First of all, measurements of SEVIRI always provide a snapshot of the current state of the atmosphere and therefore contain also clouds that are still in the process of glaciation, which occurs at timescales of the order 


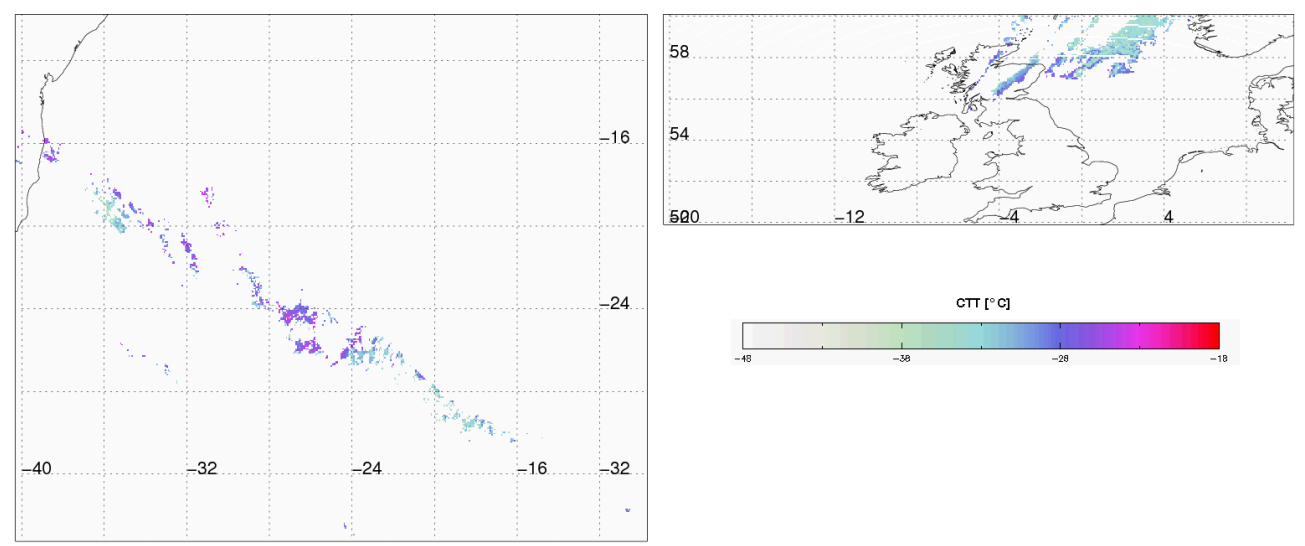

Fig. 5. High opaque clouds with liquid water on top; left: over ocean (10 October 2009, 11:45 UTC)); right: British Isles land and ocean (20 October $2009,11: 45 \mathrm{UTC}$ ), only pixels with CTT $>-38^{\circ} \mathrm{C}$.

of a few minutes (Ansmann et al., 2009) or even up to tens of minutes depending on certain atmospheric conditions such as ice nuclei concentration or updraft velocities (Korolev and Isaac, 2003). From the experimental side, supercooled liquid water can be found in clouds down to temperatures of $-37.5^{\circ} \mathrm{C}$, as was experimentally proven by Rosenfeld and Woodley (2000). They conducted in situ aircraft measurements in deep convective clouds and found that most of the condensed water remained liquid until $-37.5^{\circ} \mathrm{C}$. The amounts of detected liquid water content were not negligible with values between 0.4 and $4.0 \mathrm{~g} \mathrm{~m}^{-2}$ measured during several passages through the same cloud fields. This suggests, that the large amounts of supercooled water are not transient features. Freezing times were about $7 \mathrm{~min}$. Rosenfeld and Woodley (2000) suggest that in those cases heterogeneous freezing plays a minor role and homogeneous freezing is the main glaciating mechanism. In a further study by Khain et al. (2001), the mechanisms leading to these supercooled cloud water droplets are simulated with the bin microphysics Hebrew University cloud model (HUCM). Supercooled water at low temperatures was most often found for cloud fields with high cloud condensation nuclei number concentrations together with high vertical velocities. The authors argue that the existence of large amounts of liquid water at heights up to 9 to $10 \mathrm{~km}$ seems to be a common feature of deep vigorous convective clouds, but is not often modelled by cloud modellers due to gaps in knowledge and a lack of parameterisations for some microphysical processes. Particularly the rate of drop freezing seems to be overestimated significantly, mostly in the temperature range from -32 to $-38^{\circ} \mathrm{C}$.

Another question arises when dealing with multialgorithm data: could the cloud phase attached to the cloudy pixels that were identified as, for example, high opaque be erroneous? In the present study, CFC and LWP are derived with different algorithms and so are inconsistent in a numerical sense, so it might be possible, that the phase "liquid" is attached falsely to a cloudy pixel.
To be more precise, the CTT provided from the cloud detection algorithm is not entirely the same as the CTT that was used for the retrieval of LWP. Therefore some discrepancies in individual pixels can occur with CTT $<-38^{\circ} \mathrm{C}$ and cloud phase set as liquid. The number of falsely classified pixels is very low, about $4.0 \times 10^{-3} \%$ in our considered months.

Also the number of high clouds that are flagged as liquid is fairly small compared to the other cloud types. To make our results more plausible, we further restricted the fields for October 2009 using the corresponding CTT. Cloudy pixels of liquid phase were only considered to be valid if the cloud top temperature was warmer than $-38^{\circ} \mathrm{C}$.

In Fig. 5 a typical example of CTT for day 22 of October 2009 is shown. Only the pixels with high opaque clouds and phase liquid plus the restriction of CTT $>-38^{\circ} \mathrm{C}$ are displayed. We found that the pixels are not randomly distributed, but form contiguous areas. Also the pixels are not preferably situated in regions with high viewing angles, where the detection of clouds becomes more complicated due to the slant viewing geometry. High opaque liquid cloud pixels are found both over water as well as over land, as can be seen in the cloudy regions in Fig. 5. On the left hand side the pixels lie over water, on the right hand side the cloudy patches can be found both over water and over land. No dependence on the underlying surface could be found.

The number of pixels with high opaque clouds and liquid water and $\mathrm{CTT}>-38^{\circ} \mathrm{C}$ is much smaller compared to other cloud types for the same conditions. When averaging the data for October 2009, the cloudy pixel that satisfy the above conditions consist of $87.3 \%$ low clouds, $3.6 \%$ middle level clouds, $0.24 \%$ high opaque clouds and $8.8 \%$ high semitransparent clouds. So the number of high opaque pixels is approximately $7 \%$ of the number of middle level clouds. Still the number is not negligible, and somewhat corroborates the findings of Khain et al. (2001). A more detailed analysis of this subject can be found in Hogan et al. (2004). The authors measured the global distribution of supercooled 
water clouds by analysing data from the Lidar In-space Technology Experiment (LITE). The lidar, which was mounted on a space shuttle had the advantage of providing a view from above, as a satellite instrument does and so delivers results that are suitable for comparison with our data. In this study, the highest amounts of the coldest supercooled clouds were found in the midlatitudes of the Northern and Southern Hemisphere, but not in the region of the Intertropical Convergence Zone. Also Hu et al. (2010), who studied the occurrence of supercooled water clouds with CALIPSO found supercooled clouds mainly in the mid- or high-latitudes, associated with storm-track regions. This corresponds roughly to our findings for October 2009, but a more careful study with a broader database would have to be made.

\subsection{Diurnal cycle}

Directly from the level 2 data, monthly averaged diurnal cycles of LWP were created per cloud type for the Northern Hemisphere of the SEVIRI disc. Only cloudy pixels were averaged, i.e. we consider the intrinsic diurnal cycle of LWP. The local time of the individual data points was taken into account by sorting the pixels into time zones. In Fig. 6 the results for October 2009 are displayed; it should be noted that the algorithm yields results during daylight only, that is, where the solar zenith angle and the viewing angle of SEVIRI are smaller than $72^{\circ}$. Additionally, the average diurnal cycles are only displayed when the number of observations for the individual hours was not smaller than $1 \%$ of the average number of observations. We also considered only the hour for which the retrieval was made, not the minutes, so 11:45 a.m. at $0^{\circ}$ longitude would be sorted into 11:00 a.m. for example, which leads to slightly asymmetric curves. The LWP shows diurnal variations for all cloud types, with the middle level and high opaque cloud types having the biggest amplitude. The LWP of low clouds shows maximal values in the morning hours and around midday, whereas middle level clouds peak in the afternoon (local time). The diurnal amplitude of low clouds is very pronounced in the Northern Hemisphere; not only in October but on average it reaches $29.1 \%$ of the mean LWP and at maximum, which is in April, $56 \%$ of the mean LWP value (not shown in Fig. 6). Pfeifroth (2009) analysed the diurnal variation of CFC from SEVIRI generated by CM SAF for the year 2008 and found that the average $\mathrm{CFC}$ has a relative diurnal cycle of less than $30 \%$ of the average CFC for $58.5 \%$ of all considered pixels in the Northern Hemisphere. In relative terms, this indicates that LWP can be more variable than the cloud fraction from SEVIRI during a day. LWP and CFC fluctuations cannot be compared directly; CFC fluctuations for example result only from variation in the horizontal direction, whereas LWP is a result of variability in three dimensions. Nevertheless both kinds of fluctuation cause variations in cloud optical thickness which again influences the radiative budget. The effect of intrinsic and external COT fluctuations on the radiative budget could

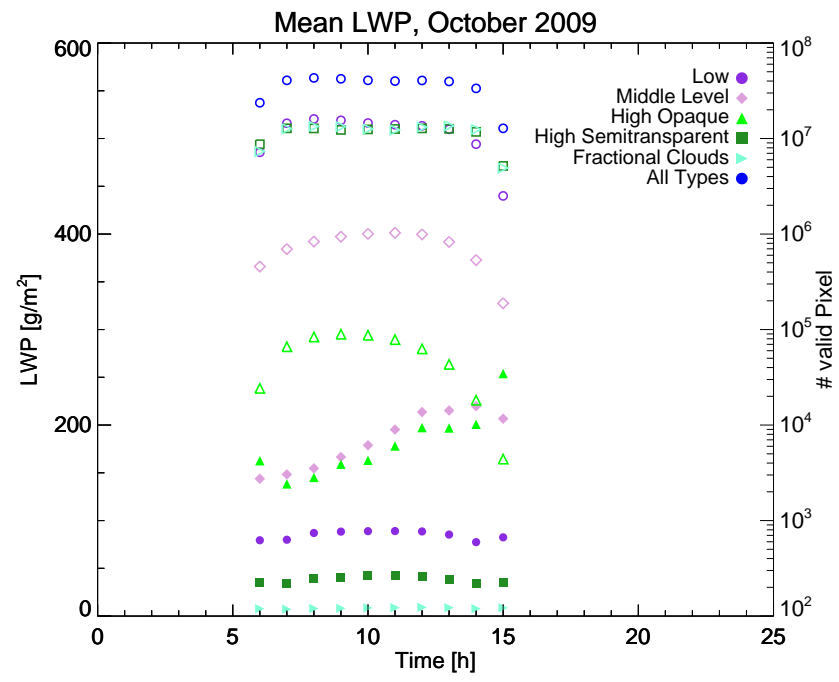

Fig. 6. Average diurnal cycle of LWP for distinct cloud types (filled symbols) and the corresponding number of occurrence (corresponding open symbols), October 2009. Level 2 data from the Northern Hemisphere of SEVIRI disc were considered; cloud-free pixels were not included in the average, i.e. variations in the average are caused by intrinsic LWP variability.

directly be compared. Further studies are required to confirm the observations and to analyse the effect on cloud optical thickness or the radiative budget, respectively.

In Fig. 6, also the number of observations is depicted, to illustrate the dependence of the CPP algorithm on the illumination conditions. For solar zenith angles above $72^{\circ}$ no useful information can be retrieved for the liquid water path and so in conjunction with the viewing geometry of the geostationary MSG 2 satellite the number of observations is mainly dependent upon the time of day, or rather the length of an individual diurnal cycle is dependent on its latitude. With averaging over a large area with a large latitude range individual characteristics of cloud fields are lost, but the objective at this point of the article is to demonstrate the overall properties of the diurnal cycle seen by SEVIRI, the analysis will be focused on smaller areas below.

Marine-boundary-layer clouds are a major source of uncertainty for cloud radiative feedbacks, as stated in several publications (see Chlond et al., 2004, Seethala and Horváth, 2010 or Wood and Hartmann, 2006). Therefore, the climate modelling community would greatly benefit from accurate LWP measurements of marine-boundary-layer clouds. Since those clouds are relatively optically thin, their radiative impact is very sensitive to their vertically integrated liquid water content (i.e. the LWP) (Turner et al., 2007). The cloud deck off the coast of Africa, approximately at Namibia and Angola serves as an example of marine-boundary-layer clouds that consist mainly of water. This special region shall be considered in more detail. Therefore, a field between $5^{\circ} \mathrm{W}-15^{\circ} \mathrm{E}$ and $30^{\circ} \mathrm{S}-10^{\circ} \mathrm{S}$ was cut from the MSG data 

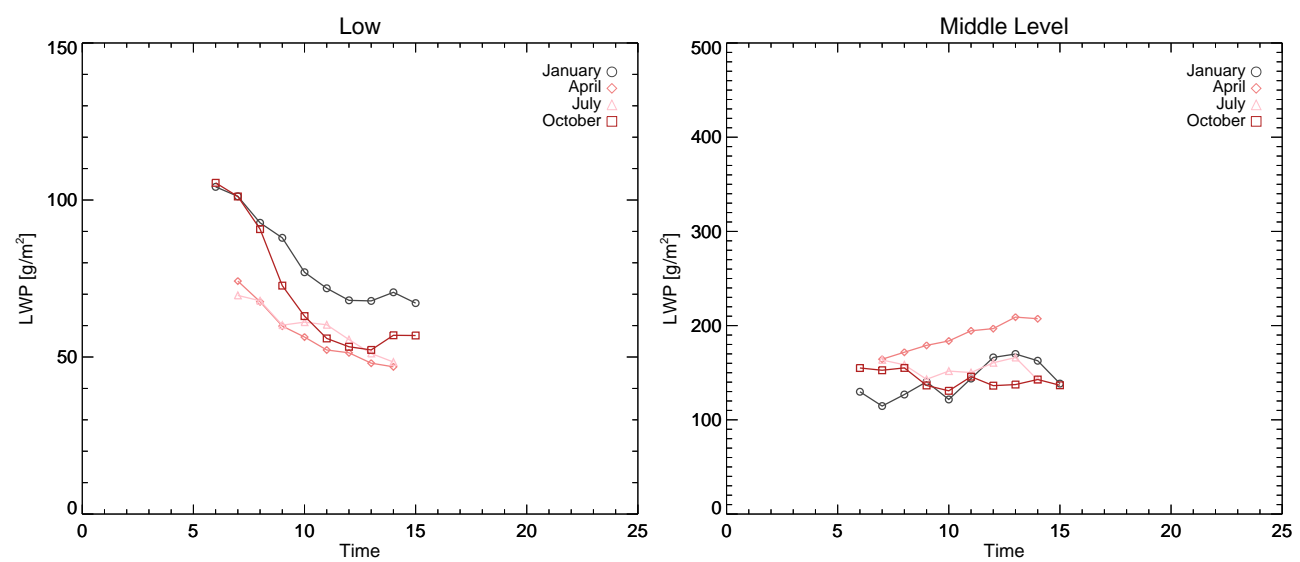

Fig. 7. Average intrinsic diurnal cycle of LWP for 4 months in 2009 for the cloud deck off the coast of Namibia and Angola; left: low clouds; right, middle level clouds. Cloud-free pixels were not included.

(compare Fig. 1) for LWP and CTY. Level 2 data from the months of January, April, July and October were averaged to form monthly mean diurnal cycles for the respective cloud types.

In Fig. 7 the average diurnal cycle of low and middle level clouds for the cloud deck is shown. As can be seen on the left hand side, the diurnal cycle of low clouds shows a strong morning maximum, tending to decrease during the day and then increase again at around 02:00 p.m. local time. This is valid for the months January, April, July and October. Diurnal variation similar to this is caused by solar absorption where the cloud top is heated during daytime, which leads to the evaporation of cloud droplets which in turn leads to evaporation cooling and subsidence of air parcels from the cloud top and thinning of the cloud cover (Chlond et al., 2004). On the other hand, radiative short-wave heating diminishes the vertical temperature gradient in the clouds and inhibits vertical motion (Chlond et al., 2004). This diurnal cycle can be simulated for example with a large eddy simulation model by including short-wave heating (Chlond et al., 2004). A similar behaviour was also observed with the imager on geostationary GOES 9 off the coast of California (Greenwald and Christopher, 1999), where a low stratocumulus field exists similar to the one off the western coast of Africa. Wood et al. (2002) propose fitting coefficients for the diurnal cycle of LWP for low clouds. The fitting coefficients in Wood et al. (2002) for a sinusoidal curve were derived from the microwave radiometer data of the TMI (Tropical Rainfall Measuring Mission Microwave Imager), yet our findings confirm that this would be a valid approach. The middle level clouds on the right hand side do not show such a constant shape of diurnal cycle; in January and April the maximal value is reached in the early afternoon, whereas in July and October the maximal values appear in the morning, although the maxima were quite unpronounced.

Here we consider the possibility of particular clouds to develop during a day, for example, through convective development and changing its cloud type class. To illustrate this effect, we analysed the above mentioned region off the coast of Africa, which should provide a temporally stable cloud layer. Stable is meant in a sense that this layer stays in more or less the same geographic location and CFC is roughly constant in the time frame of a month. Hence the observed changes in CTY and LWP should result mainly due to internal developments of the cloud deck during daytime. In Fig. 8, the average diurnal cycle of LWP together with the number of observations is displayed for the cloud deck in April 2009. The LWP of low clouds is highest in the morning hours and decreases during daytime, also the number of observed low clouds decreases until 12:00 LT and increases afterwards. The numbers of middle level and high semitransparent clouds show a similar development. At the same time the number of fractional clouds increases to reach a maximum at 11:00 LT, plus the number of high opaque clouds increases until 10:00 LT before decreasing again. Because the cloud deck as a whole is fairly stationary, this indicates a transition of clouds from one type to another in this region. We are aware that this study can give only a rough impression on the possibility of cloud class transition and that a temporally and spatially much higher resolved analysis would be needed to make a more quantitative declaration for this specific region. For example we neglected the possibility that high clouds can obscure lower cloud layers and a clearing of high clouds makes the lower layers detectable for SEVIRI which in turn changes the number of detected low clouds.

For further characterisation, the diurnal cycles of LWP derived from SEVIRI were compared to climatological diurnal cycles derived from passive microwave observations (O'Dell et al., 2008). From this climatology a small subset was processed for our region specified above. We show comparisons only for this region because the probability for mixed-phase and ice clouds is low. LWP in mixed-phased clouds is detected by microwave observations and cannot be filtered from the climatology. In Fig. 9 a direct comparison 


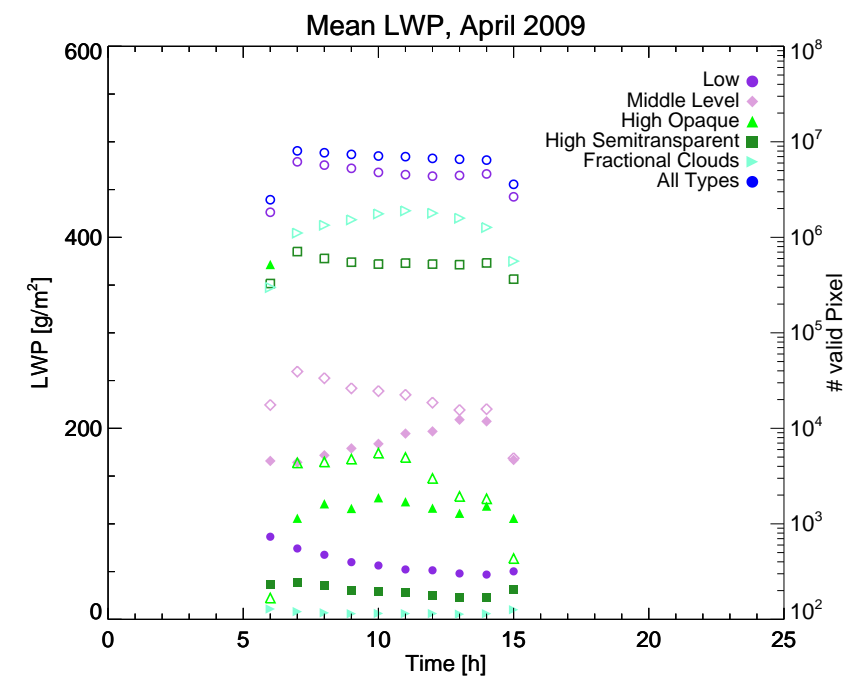

Fig. 8. Filled symbols: average intrinsic diurnal cycle of LWP for distinct cloud types in the cloud deck off the coast of Namibia and Angola, April 2009; corresponding open symbols: respective number of observations.

between the SEVIRI derived LWP values and the microwave measurements (aggregated from SSM/I, TMI and AMSR-E data) can be found. The microwave data are climatological average values from the years 1988-2008, the SEVIRI data are monthly averages from the year 2009. For a better comparability also cloud-free pixels were included for the SEVIRI data and no distinction between cloud types was made, although clouds in this region are mostly of low type. Additionally, there was no cloud edge removal in the SEVIRI data in order to give the best consistency with the O'Dell climatology where a mixed signal from cloudy and cloud-free portions is measured with a pixel size of $2.5^{\circ} \times 2.5^{\circ}$ as opposed to $0.05^{\circ} \times 0.05^{\circ}$ from CLAAS. As can be seen, the shape of the diurnal cycles derived from SEVIRI corresponds reasonably well with the diurnal cycles derived from the climatology, especially if the times near sunrise are not considered. Particularly April and July show a good agreement in terms of both the shape and magnitude for all the times of the day available. Close to the sunrise and sunset hours, the deviations increase. This is caused by two effects: first, the quality of LWP retrieved from SEVIRI is reduced at high solar zenith angles mainly due to the plane-parallel bias as described in Sect. 2.2 (see also Varnai and Davies, 1999) and second the climatology of O'Dell was fitted with a sine curve, which can lead to increasing differences where $\sin (x)$ is close to 1 .

The absolute values from the SEVIRI measurements are higher for all months. Since the SEVIRI measurements only cover individual months of the year 2009 and the microwavederived diurnal cycles are based on a 20 year climatology a quantitative comparison should not be made. Therefore we will discuss briefly the expected accuracy of the retrieved LWP values. Wood et al. (2002) compared the microwave
LWP data set from which the climatology was derived with MODIS measurements. Coinciding overpasses from two months of data were directly compared, the bias was found to be $10.0 \mathrm{~g} \mathrm{~m}^{-2}$ with an RMS difference of $17.0 \mathrm{~g} \mathrm{~m}^{-2}$. CLAAS LWP was also compared against MODIS for individual scenes, the bias is $1.2 \mathrm{~g} \mathrm{~m}^{-2}$ and the RMS difference $38.0 \mathrm{~g} \mathrm{~m}^{-2}$, the probability of detection of clouds with COT $<0.1$ is 0.65 for the CLAAS data set when compared to CALIPSO (Kniffka et al., 2013b). So the deviation between CLAAS LWP and the microwave-derived LWP can be expected to be close to $10.0 \mathrm{~g} \mathrm{~m}^{-2}$ when considering co-located measurements. The observed deviation of the SEVIRI measurements from 2009 and the microwave climatology lies in the range of $2-40 \mathrm{~g} \mathrm{~m}^{-2}$ and can be explained by yearly fluctuations. For the retrieval of LWP from SEVIRI, the common assumption that liquid water content (LWC) is constant with height was applied. Wood and Hartmann (2006) applied in their study on LWP in marine low clouds a LWC profile that linearly increases with height as is often observed in marine stratiform cloud cover. The profile assumption was applied to MODIS measurements in their case which is quite comparable to the SEVIRI instrument and LWP retrieval. The LWP was reduced by a factor of $5 / 6=0.83$ in that study. Application of this LWC-profile to SEVIRI data would shift the 2009 data to the microwave data, but since the latter is a climatology and the deviation in an acceptable range, no attempt is done for the present study. Chellappan (2011) compared CM SAF LWP to TMI in the South Atlantic, including our region of interest, together with aerosols. They also found generally higher LWP values derived from SEVIRI, where a better agreement occurs during unpolluted episodes. As can be seen on the right hand side of Fig. 9, with SEVIRI it is possible to provide high temporal resolution diurnal cycles for the whole of a given day, so also the temporal fluctuation of the diurnal cycles during, for example, a month can be studied in contrast to measurements from polar orbiting instruments.

The diurnal cycle of LWP is created by either the intrinsic fluctuations of LWP within a cloud field or by the macroscopic change of cloud cover, i.e. the absence or presence of clouds in this respect. In Fig. 10 we refined the diurnal cycle description by splitting the average diurnal cycle into contributions from these two parts. The intrinsic share is determined by averaging over all pixels with $\mathrm{LWP}>0.0 \mathrm{~g} \mathrm{~m}^{-2}$. The macroscopic change in cloud cover is assessed by creating masks for which a value of 1 is given for a pixel with LWP $>0.0 \mathrm{~g} \mathrm{~m}^{-2}$ and 0 for pixels without clouds or with ice, subsequently the average of all those pixels in the mask is calculated. For a better comparability, the resulting diurnal cycles are displayed in Fig. 10 relative to their mean values. The intrinsic diurnal cycle represented by the filled stars can easily be described as sinusoidal with a maximum in the morning hours and a minimum in the afternoon. The liquid cloud fraction contribution (open circles) has two maxima; one in the morning and one in the late afternoon with a minimum at midday. As pointed out before, 

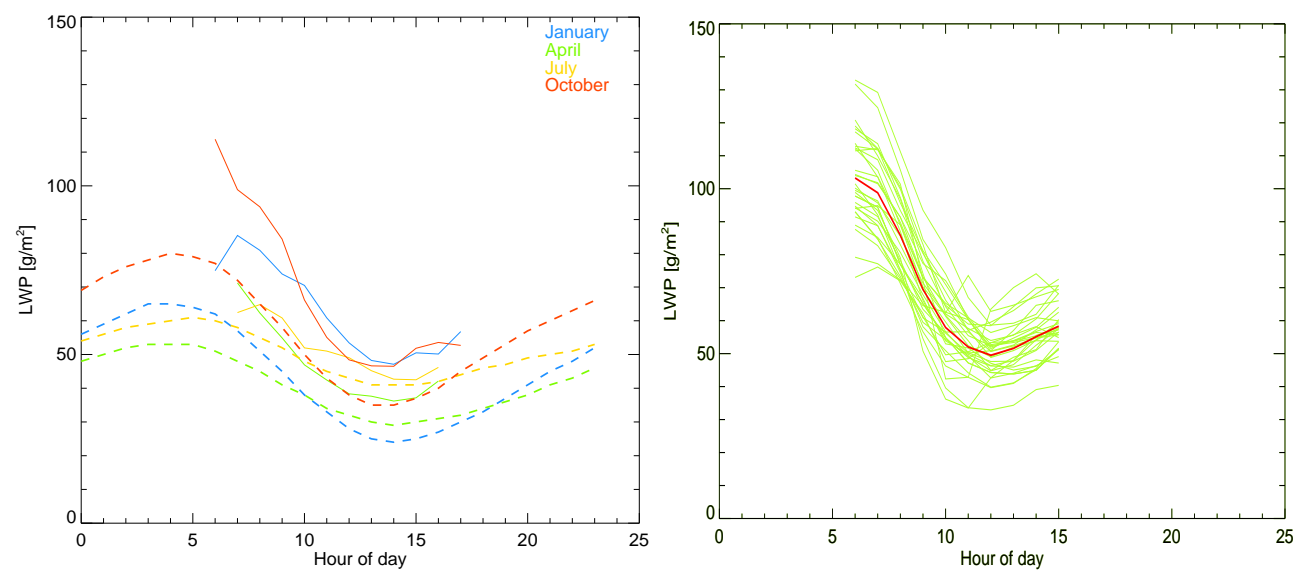

Fig. 9. Left: average diurnal cycle of LWP for 4 months in 2009 from SEVIRI (solid lines) compared to climatological values of 1988-2008 derived from microwave measurements (dashed lines), all cloud types in the low cloud deck off the coast of Namibia and Angola. Right: individual diurnal cycles for October 2009 as seen from SEVIRI, spatially averaged over the low cloud deck region (compare Fig. 1), also cloud-free pixels were included in the average for consistency with the microwave LWP climatology.
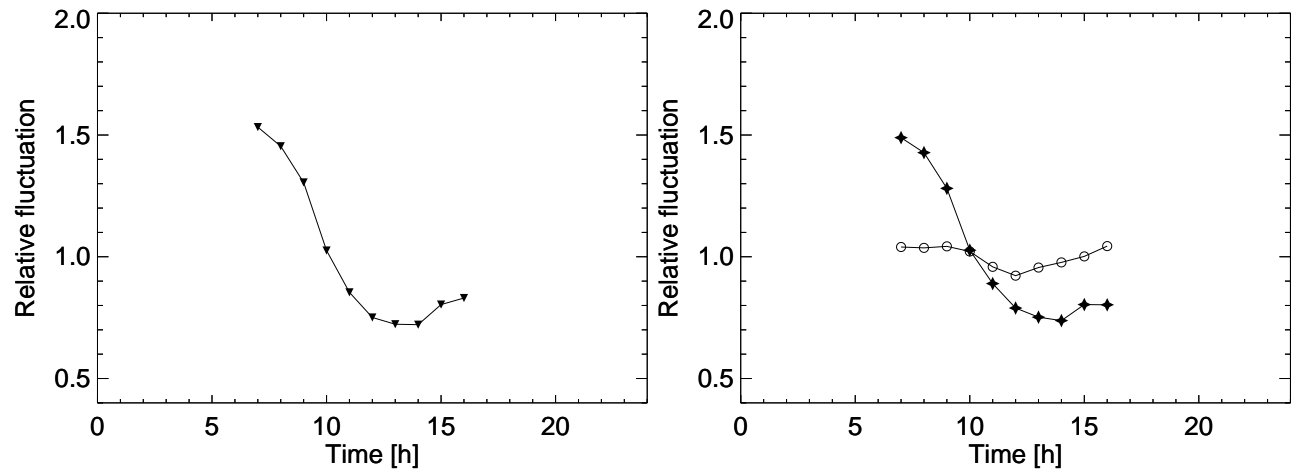

Fig. 10. Left: relative diurnal cycle of LWP of all clouds in the low cloud deck off the coast of Namibia and Angola as seen from SEVIRI in October 2009. Right: relative diurnal cycle split into the intrinsic variability of LWP (black stars) and the variability caused by cloud fraction fluctuation.

the relative amplitude of the intrinsic fluctuation is greater than the macroscopic fluctuation of cloud cover in this region. This example demonstrates that it is possible to distinguish between different sources of variability in the overall LWP diurnal cycle when monitoring with SEVIRI. The analysis of the possible consequences on, for example, the energy budget or the transformation of cloud cover on longer timescales remains to be elucidated.

The final step of the diurnal cycle considerations is the mapping of the intrinsic amplitude of the LWP cycle for the entire SEVIRI field of view.

In Fig. 11 the relative intrinsic amplitude of the daylight cycle of low clouds on the complete SEVIRI field of view is displayed together with the local time of the maximal LWP value. The measurements were averaged over one month and regridded to $36 \times 36$ SEVIRI pixel. The amplitude is expressed in relative terms, that is, amplitude weighted with the average LWP of the grid box and the results for April are displayed. In the Atlantic Ocean west of the African Continent, the relative amplitude tends to be lower than over land, with the exception of the Sahara, where the overall lowest values of the relative amplitude can be found. Since the cloud fraction of any cloud type is so small in the North African region, it will be excluded from the discussion. Particularly in the cloud deck off the coast of Namibia and Angola the relative amplitude is low and forms a patch like structure. Further west towards South America the amplitude increases and reaches values comparable to that over the African continent or higher. The highest relative amplitude can be found in the Mediterranean Sea. On the right hand side of Fig. 11 the corresponding local time of the maximal value of the daylight cycle of LWP for low clouds is displayed. In the cloud deck off the coast of Namibia and Angola the maximal LWP appears in the morning hours around 8 a.m. and 9 a.m., also on the northwest African coast and the northeast coast of South America the maximum appears early. In the other regions, the maximum tends to be later during the day but not later than 1 p.m. 

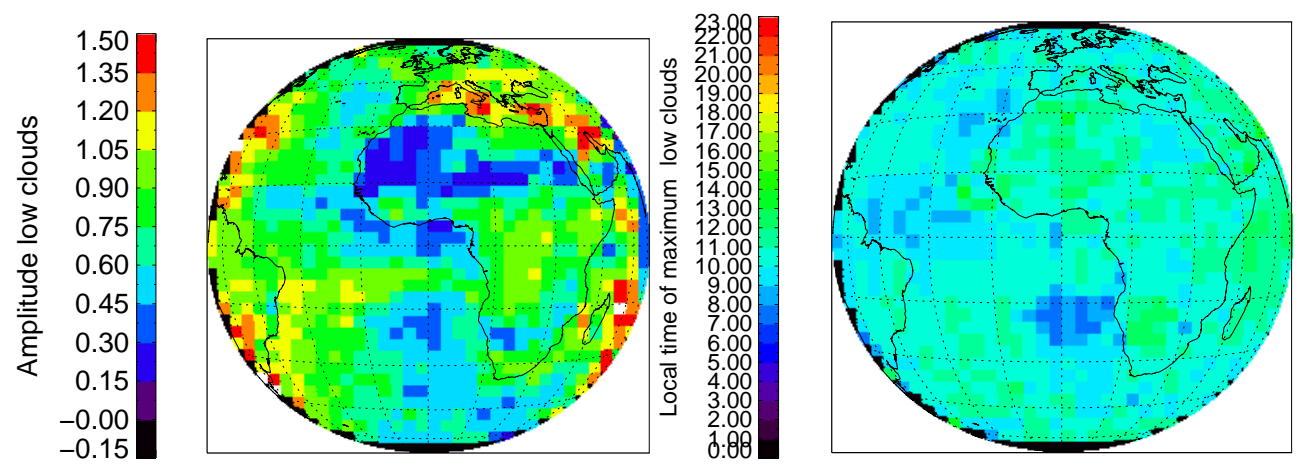

Fig. 11. Left: relative amplitude of the intrinsic LWP cycle of low clouds for April 2009. Right: local time of the maximum of low cloud LWP in the diurnal cycle for April 2009. One grid box contains $36 \times 36$ SEVIRI pixels, all LWP fields or April 2009 were averaged.
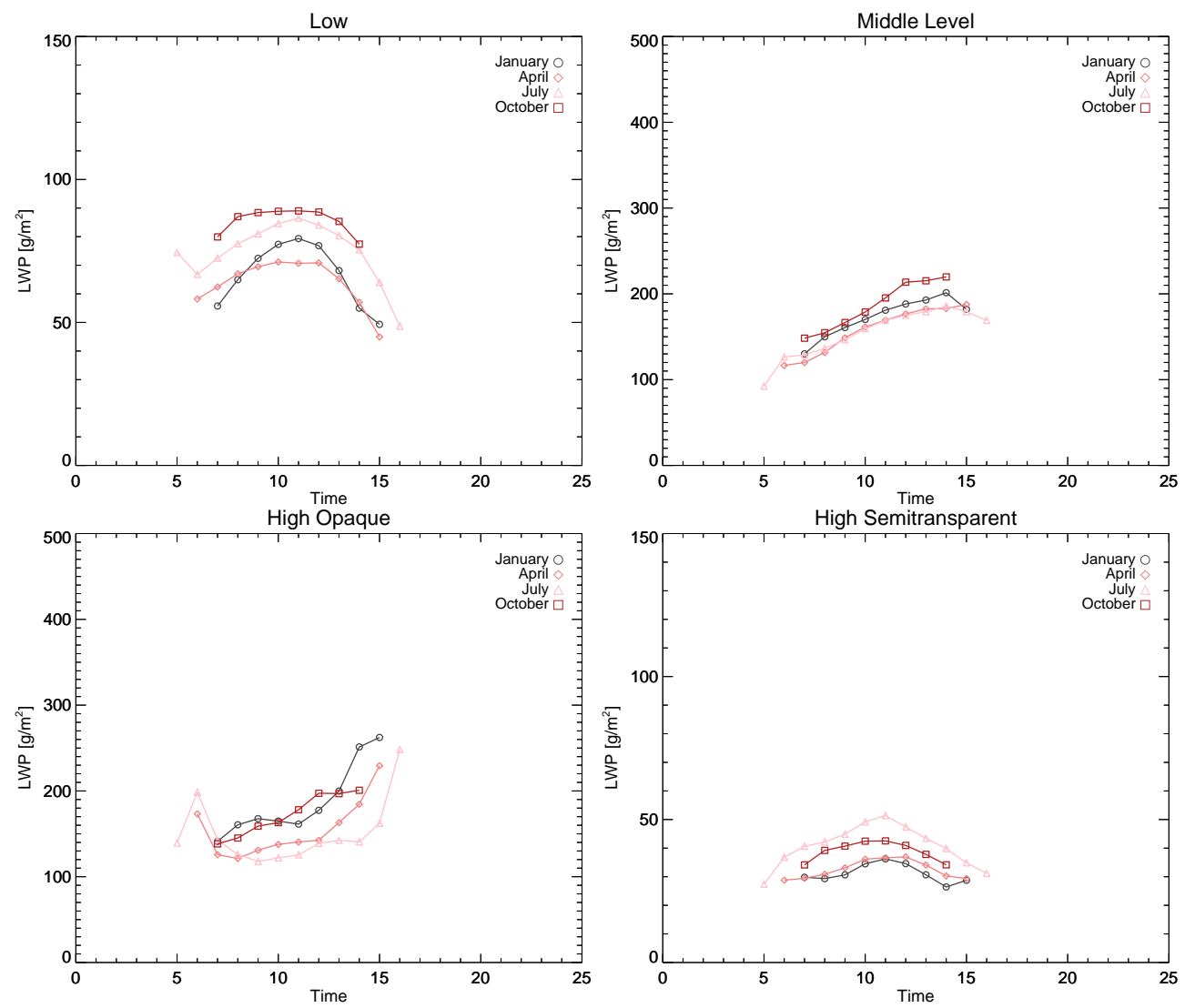

Fig. 12. Average diurnal cycle of LWP from 4 months in 2009 for the Northern Hemisphere in the MSG disc; upper left: low clouds; upper right, middle level clouds; lower left: high opaque clouds and lower right: high semi-transparent clouds. Cloud-free pixels were not averaged.

\subsection{Seasonal variation}

To complete the picture, the average intrinsic diurnal cycles of low, middle level, high opaque and high semitransparent clouds in the Northern Hemisphere are displayed in Fig. 12.

The seasonal variation is present for all cloud types in the Northern Hemisphere. Predominantly a shift of LWP from one season to another can be detected for all cloud types. In the case of low clouds or middle level clouds the highest mean values are found in October and the lowest in April. High semitransparent clouds show a maximum in July and a minimum in January. Not only the mean values fluctuate with time, but also the shape of the diurnal cycle. High opaque clouds are variable in this respect, in the months January and October a local maximum can be observed in the first half of the day, and in April and July a local maximum appears in the second half of the day. This qualitative difference indicates that the cloud formation mechanisms are 
complex and vary with time. Even though these differences are not very pronounced, they are observable when averaging over this large area.

The shape of the diurnal cycle of the other cloud classes is rather constant during the four seasons.

Contrary to the marine region considered before, the low clouds here do not possess a pronounced morning maximum, a more striking feature is the second one around midday, which is also the absolute maximum in the considered months.

\section{Conclusions}

In this study we analysed the occurrence of LWP depending on cloud type. The objective was to find characteristic features of LWP for the individual cloud types. The general features of LWP, for example frequency distribution, average value and diurnal cycle are specified to serve as characteristic measures in atmospheric numerical modelling. With these measures, studies for a better description of LWP distribution in models under varying conditions, as for example performed by de Roode and Los (2008), are facilitated. Other possible applications are process studies or input data for cloud generators (Venema et al., 2006) and radiative transfer studies on a wide range of spatial scales. They can also provide verification in microphysical measurement experiments such as the airborne probing of clouds.

Each cloud type possesses a characteristic average LWP distribution that is rather constant with time for the complete area observed by MSG, but variable for smaller regions, for example, Europe. The fact, that the distributions do not change with time when considering the full disc shows that the disc is big enough to cover all cases so the statistics derived from such a large spatial field is robust and general for most applications. Also the two retrieval algorithms, msgv2010 and CPP v3.9 are independent enough, so that one scheme does not limit the sample space of the other: LWP is derived by applying the Nakajima and King scheme using the 0.6 and $1.6 \mu \mathrm{m}$ channels. The CTY algorithm does not use the $1.6 \mu \mathrm{m}$ channel, but together with 6 other channels, the $0.6 \mu \mathrm{m}$ channel is needed to distinguish high semitransparent or fractional clouds from the more opaque cloud types. However, for both thin cloud types several tests are applied which always include the radiance of $0.6 \mu \mathrm{m}$, either below or above the same threshold. Hence the use of the $0.6 \mu \mathrm{m}$ channel does not influence the frequency distribution of the individual cloud types. We studied the diurnal cycle of liquid water path for the entire year 2009 and found that the diurnal cycle is dependent on cloud type. It has to be noted that clouds can develop during a day leading to a different type assignment by the retrieval. So clouds can change from one cloud type class into another, that is, the diurnal cycle of LWP of a certain cloud type should be interpreted as being composed of the liquid water content averaged over all clouds of one type that are existing at the individual points in time.

The diurnal cycle of low clouds in the region off the coast of Angola and Namibia seems to be driven mainly by solar absorption. A numerical verification of cloud development through short-wave heating via large eddy simulation can be found in Chlond et al. (2004). Maps of the relative amplitude of low clouds and the local time of maximum LWP for the SEVIRI disc revealed, that the amplitude as well as the maximum time are not constant but show spatial patterns, where the time of maximum LWP varied from morning to midday but not later than 1 p.m. and the amplitude was largest in the Mediterranean Sea and lowest in the low cloud deck off the coast of Namibia and Angola.

The diurnal cycle of middle level and high opaque clouds is more characteristic of convective development, with the clouds developing during the day and containing more liquid water in the afternoon. Please be aware that when considering the complete SEVIRI disc only a rough average is provided, which sums up all possible mechanisms of cloud development in just one curve per cloud type. Still we would consider these curves to be a useful approximation that can serve as prototype clouds in large-scale numerical process studies or simulations on longer timescales because on the whole, the energy cycle or radiative cycle can be described correctly with these approximations. Due to the variety of process that are mixed in regions with frequent frontal system transits, the choice of averaging domain has a considerable effect on the observed diurnal cycles of LWP in case the domains are chosen small. For regions where one cloud type predominates and whose development is at the same time mainly driven by one process, SEVIRI-derived diurnal cycles of cloud parameters are obviously best comparable with models, e.g. regional climate models, since the number of complications is as small as possible. This is also observed in Roebling and Van Meijgard (2009) and Pfeifroth et al. (2012) who compared SEVIRI-derived cloud parameters to the regional climate models RACMO2 (Regional Atmospheric Climate Model version 2) and COSMO-CLM. Roebling and Van Meijgard (2009) found a good agreement between diurnal cycle amplitudes of cloud amount LWP for Europe, where they subdivided the domain into several regions with distinct climatic features such as mediterranean stratocumulus region. In the subregions, differences between model and measurement varied and could be traced back to various process that were covered or not covered by the model. In the present study we found and presented temporally stable average shapes of the diurnal cycle of LWP depending on cloud type for large areas such as the Northern Hemisphere and also found pronounced spatial variations of the amplitude and time of maximum.

A drawback is the typical problem of an imager mounted on a geostationary satellite: the cloud amount and also the liquid water path is dependent on the viewing geometry, and so the error increases towards the rims of the disc. The line of 
sight of SEVIRI is more slanted towards the rims of the field of view, that is, gaps between clouds cannot be seen properly any more because one cloud field obscures another. Therefore the overall cloud fraction is detected too high towards the rims of the disc. Since the liquid water path is a volumetric variable, it is not only affected by the obscuring of cloud gaps but also the impossibility of detecting inhomogeneities within clouds along the line of sight. So the retrieval error for LWP is not systematical but depends on the spatial structure of the cloud fields. A stratiform, homogeneous field will have a smaller error than a cumulus cloud cover, particularly with sub-pixel homogeneity. A more extensive evaluation on the rim effects, for example, error depending on cloud types, will be done in the future.

It is particularly noticeable that the relative amplitude of the LWP diurnal cycle can exceed that of CFC. This aspect needs further analysis and careful error assessment. Particularly the fluctuations of cloud optical thickness that result either from fluctuations of LWP or from CFC are of interest, to better quantify the absolute effect caused by fluctuations in the two quantities. Therewith the impact on radiative quantities such as heating rates or cloud radiative forcing will be assessed in future studies. In Wood et al. (2002) the normalised amplitude of the simultaneously retrieved low cloud amount is $50 \%$ less than the LWP amplitude in subtropical regions. But short-wave radiative transfer calculations showed that the cloud amount diurnal cycle has a 2-3 times larger influence on morning-afternoon differences in top of atmosphere short-wave radiative forcing. In this context, the impact of the diurnal variations of LWP and CFC should be considered in more detail.

In further analysis ice water path will be included, to investigate the effect of phase transition during the development of clouds, particularly convective cloud systems will be of interest.

Acknowledgements. This work was carried out within the framework of EUMETSAT's Satellite Application Facility on Climate Monitoring (CM SAF) in cooperation with the national meteorological institutes of Germany, Sweden, Finland, the Netherlands, Belgium, Switzerland, and the United Kingdom.

The authors would like to thank all reviewers for the valuable comments and discussion points.

Edited by: A. Macke

\section{References}

Ansmann, A., Tesche, M., Seifert, P., Althausen, D., Engelmann, R., Fruntke, J., Wandinger, U., Mattis, I., and Muller, D.: Evolution of the ice phase in tropical altocumulus: SAMUM lidar observations over Cape Verde, J. Geophys. Res., 114, D17208, doi:10.1029/2008JD011659, 2009.

Barker, H. W., Stephens, G. L., and Qiang Fu: The sensitivity of domain-averaged solar fluxes to assumptions about cloud geometry, Q. J. Roy. Meteorol. Soc., 125, 2127-2152, 1999.

Bony, S. and Dufresne, J.-L.: Marine boundary layer clouds at the heart of tropical cloud feedback uncertainties in climate models, Geophys. Res. Lett., 32, L20806, doi:10.1029/2005GL023851, 2005.

Brunke, M. A., de Szoeke, S. P., Zuidema, P., and Zeng, X.: A comparison of ship and satellite measurements of cloud properties with global climate model simulations in the southeast Pacific stratus deck, Atmos. Chem. Phys., 10, 6527-6536, doi:10.5194/acp-10-6527-2010, 2010.

Bugliaro, L., Zinner, T., Keil, C., Mayer, B., Hollmann, R., Reuter, M., and Thomas, W.: Validation of cloud property retrievals with simulated satellite radiances: a case study for SEVIRI, Atmos. Chem. Phys., 11, 5603-5624, doi:10.5194/acp-11-5603-2011, 2011.

Chellappan, S.: Evaluating the diurnal cycle of clouds using CMSAF SEVIRI VIS/NIR and TMI microwave retrievals, CM-SAF VS/AS19 final report, CLM_AS10_p06, 2011.

Chlond, A., Müller, F., and Sednev, I.: Numerical simulation of the diurnal cycle of marine stratocumulus during FIRE - A LES and SCM modeling study, Q. J. Roy. Metorol. Soc., 130, 3297-3321, 2004.

Considine, G., Curry, J. A., and Wielicki, B.: Modeling cloud fraction and horizontal variability in marine boundary layer clouds, J Geophys. Res., 102, 13517-13525, doi:10.1029/97JD00261, 1997.

Dee, D. P., Uppala, S. M., Simmons, A. J., Berrisford, P., Poli, P., Kobayashi, S., Andrae, U., Balmaseda, M. A., Balsamo, G., Bauer, P., Bechtold, P., Beljaars, A. C. M., van de Berg, L., Bidlot, J., Bormann, N., Delsol, C., Dragani, R., Fuentes, M., Geer, A. J., Haimberger, L., Healy, S. B., Hersbach, H., Hólm, E. V., Isaksen, L., Kållberg, P., Köhler, M., Matricardi, M., McNally, A. P., Monge-Sanz, B. M., Morcrette, J.-J., Park, B.K., Peubey, C., de Rosnay, P., Tavolato, C., Thépaut, J.-N., and Vitart, F.: The ERA-Interim reanalysis: configuration and performance of the data assimilation system, Q. J. Roy. Meteorol. Soc., 137, 553-597, doi:10.1002/qj.828, 2011.

De Haan, J. F., Bosma, P., and Hovenier, J. W.: The adding method for multiple scattering calculations of polarized light, Astron. Astrophys., 183, 371-391, 1987.

de la Torre Juárez, M., Davis, A. B., and Fetzer, E. J.: Scale-by-scale analysis of probability distributions for global MODIS-AQUA cloud properties: how the large scale signature of turbulence may impact statistical analyses of clouds, Atmos. Chem. Phys., 11, 2893-2901, doi:10.5194/acp-11-2893-2011, 2011.

Derrien, M.: Météo France/Centre de Meteorologie Spatiale: Algorithm Theoretical Basis Document for "Cloud Products" (CMa-PGE01 v3.0,CT-PGE02 v2.0 and CTTH-PGE03 v2.1), SAF/NWC/CDOP/MFL/SCI/ATBD/01, Version 3, Rev. 0, 2010.

Derrien, M. and Le Gléau, H.: MSG/SEVIRI cloud mask and type from SAFNWC, Int. J. Remote Sens., 26, 4707-4732, 2005. 
Derrien, M. and Le Gléau, H.: Improvement of cloud detection near sunrise and sunset by temporal differencing and regiongrowing techniques with real-time SEVIRI, Int. J. Remote Sens., 31, 1765-1780, 2010.

de Roode, S. and Los, A.: The effect of temperature and humidity fluctuations on the liquid water path of non-precipitating closedcell stratocumulus clouds, Q. J. Roy. Meteorol. Soc., 134, 403416, doi:10.1002/qj.222, 2008.

EUMETSAT: A Planned Change to the MSG Level 1.5 Image Product Radiance Definition, EUM/OPS-MSG/TEN/06/0519, 2007.

EUMETSAT: MSG Level 1.5 Image Data Format Description, EUM/MSG/ICD/105 v6, 2010.

Greenwald, T. J. and Christopher, S. A.: Daytime variation of marine stratocumulus microphysical properties as observed from geostationary satellite, Geophys. Res. Lett., 26, 1723-1726, 1999.

Hannay, C., Williamson, D. L., Hack, J. J., Kiehl, J. T., Olson, J. G., Klein, S. A., Bretherton, C. S., and Kohler, M.: Evaluation of Forecasted Southeast Pacific Stratocumulus in the NCAR, GFDL, and ECMWF Models, J. Climate, 22, 28712889, doi:10.1175/2008JCLI2479.1, 2009.

Hogan, R. J., Behera, M. D., O'Connor, E. J., and Illingworth, A. J.: Estimate of the global distribution of stratiform supercooled liquid water clouds using the LITE lidar, Geophys. Res. Lett., 31, L05106, doi:10.1029/2003GL018977, 2004.

Hollmann, R.: Annual Product Quality Assessment Report 2010, SAF/CM/DWD/VAL/OR6, Version 1.1, 2011.

Hu, Y., Rodier, S., Xu, K., Sun, W., Huang, J., Lin, B., Zhai, P., and Josset, D.: Occurrence, liquid water content, and fraction of supercooled water clouds from combined CALIOP/IIR/MODIS measurements, J. Geophys. Res., 115, D00H34, doi:10.1029/2009JD012384, 2010

Iwabuchi, H. and Hayasaka, T.: Effects of cloud horizontal inhomogeneity on the optical thickness retrieved from moderateresolution satellite data, J. Atmos. Sci., 59, 2227-2242, 2002.

Jiang, J. H., Su, H., Zhai, C., Perun, V. S., Del Genio, A., Nazarenko, L. S., Donner, L. J., Horowitz, L., Seman, C., Cole, J., Gettelman, A., Ringer, M. A., Rotstayn, L., Jeffrey, S., Wu, T. W., Brient, F., Dufresne, J. L., Kawai, H., Koshiro, T., Watanabe, M., L'Ecuyer, T. S., Volodin, E. M., Iversen, T., Drange, H., Mesquita, M. D. S., Read, W. G., Waters, J. W., Tian, B. J., Teixeira, J., and Stephens, G. L.: Evaluation of cloud and water vapor simulations in CMIP5 climate models using NASA "A-Train" satellite observations, J. Geophys. Res., 117, D14105, doi:10.1029/2011JD017237, 2012.

Khain, A. P., Rosenfeld, D., and Pokrovsky, A.: Simulating convective clouds with sustained supercooled liquid water down to $-37.5^{\circ} \mathrm{C}$ using a spectral microphysics model, Geophys. Res. Lett., 28, 3887-3890, 2001.

Kniffka, A., Meirink, J. F., Stengel, M.: Algorithm Theoretical Basis Document SEVIRI cloud products Edition 1, SAF/CM/DWD/ATBD/SEV/CLD, Version 1.1, 2013a.

Kniffka, A., Lockhoff, M., Stengel, M., and Meirink, J. F.: Validation Report SEVIRI cloud products Edition 1, SAF/CM/DWD/VAL/SEV/CLD, Version 1.1, 2013b.

Korolev, A. and Isaac, G.: Phase transformation of mixed-phase clouds, Q. J. Roy. Meteorol. Soc., 129, 19-38, 2003.

Marshak, A., Platnick, S., Várnai, T., Wen, G., and Cahalan, R. F. Impact of three-dimensional radiative effects on satellite re- trievals of cloud droplet sizes, J. Geophys. Res., 111, D09207, doi:10.1029/2005JD006686, 2006.

McBride, P. J., Schmidt, K. S., Pilewskie, P., Walther, A., Heidinger, A. K., Wolfe, D. E., Fairall, C. W., and Lance, S.: CalNex cloud properties retrieved from a ship-based spectrometer and comparisons with satellite and aircraft retrieved cloud properties, J. Geophys. Res., 117, D00V23, doi:10.1029/2012JD017624, 2012.

Meirink, J. F., Roebeling, R. A., and Stammes, P.: Inter-calibration of polar imager solar channels using SEVIRI, Atmos. Meas. Tech., 6, 2495-2508, doi:10.5194/amt-6-2495-2013, 2013.

Meirink, J. F., Kniffka, A., Lockhoff, M., and Stengel, M.: Evaluation of cloud optical and microphysical property observations in the CLAAS dataset, Atmos. Chem. Phys. Discuss., in preparation, 2014.

O’Dell, C., Wentz, F., and Bennartz, R.: Cloud liquid water path from satellite-based passive microwave observations: a new climatology over the global oceans, J. Climate, 21, 1721-1739, 2008.

Painemal, D., Minnis, P., Ayers, J. K., and O'Neill, L.: GOES-10 microphysical retrievals in marine warm clouds: Multi-instrument validation and daytime cycle over the southeast Pacific, J. Geophys. Res., 117, D19212, doi:10.1029/2012JD017822, 2012.

Pfeifroth, U.: Tagesgang von Bewölkung in satellitenbasierten und synoptischen Beobachtungen sowie in regionalen Klimasimulationen, Institut für Atmosphäre und Umwelt, Goethe-Universität Frankfurt, 2009.

Pfeifroth, U., Hollmann, R., and Ahrens, B.: Cloud Cover Diurnal Cycles in Satellite Data and Regional Climate Model Simulations, Meteorol. Z., 21, 551-560, doi:10.1127/09412948/2012/0423, 2012.

Prospero, J. M., Charlson, R. J., Mohnen, V., Jaenicke, R., Delany, A. C., Moyers, J., Zoller, W., and Rahn, K.: The Atmospheric Aerosol System: An Overview, Rev. Geophys. Space Phys., 21, 1607-1629, 1983.

Roebeling R. A. and van Meijgaard, E.: Evaluation of the daylight cycle of model predicted cloud amount and condensed water path over Europe with observations from MSG-SEVIRI, J. Climate, 22, 1749-1766, doi:10.1175/2008JCLI2391.1, 2009.

Roebeling, R. A., Feijt, A. J., and Stammes, P.: Cloud property retrievals for climate monitoring: implications of differences between Spinning Enhanced Visible and Infrared Imager (SEVIRI) on Meteosat-8 and Advanced Very High Resolution Radiometer(AVHRR) on NOAA-17, J. Geophys. Res., 111, D20210, doi:10.1029/2005JD006990, 2006.

Roebeling, R. A., Deneke, H. M., and Feijt, A. J.: Validation of cloud liquid water path retrievals from SEVIRI using one year of CloudNET observations, J. Appl. Meteorol. Clim., 47, 206-222, 2008.

Roebeling, R. A., Baum, B., Bennartz, R., Hamann, U., Heidinger, A., Thoss, A., and Walther, A.: Third Cloud Retrieval Evaluation Workshop (CREW-3), Gewex newsletter Feb 2012, 14-16, 2012.

Rosenfeld, D. and Woodley, W. L.: Deep Convective Clouds with Sustained Supercooled Liquid Water Down to $-37.5^{\circ} \mathrm{C}$, Nature, 405, 440-442, doi:10.1038/35013030, 2000. 
Rossow, W. B. and Schiffer, R. A.: Advances in understanding clouds from ISCCP, B. Am. Meteorol. Soc., 80, 2261-2287, 1999.

Schmetz, J., Pili, P., Tjemkes, S., Just, D., Kerkmann, J., Rota, S., and Ratier, A.: An introduction to Meteosat Second Generation (MSG), B. Am. Meteorol. Soc., 83, 977-992, 2002.

Schulz, J., Albert, P., Behr, H.-D., Caprion, D., Deneke, H., Dewitte, S., Dürr, B., Fuchs, P., Gratzki, A., Hechler, P., Hollmann, R., Johnston, S., Karlsson, K.-G., Manninen, T., Müller, R., Reuter, M., Riihelä, A., Roebeling, R., Selbach, N., Tetzlaff, A., Thomas, W., Werscheck, M., Wolters, E., and Zelenka, A.: Operational climate monitoring from space: the EUMETSAT Satellite Application Facility on Climate Monitoring (CM-SAF), Atmos. Chem. Phys., 9, 1687-1709, doi:10.5194/acp-9-1687-2009, 2009.

Schutgens, N. A. J. and Roebeling, R. A.: Validating the validation: the influence of liquid water distribution in clouds on the intercomparison of satellite and surface observations, J. Atmos. Ocean. Tech., 26, 1457-1474, doi:10.1175/2009JTECHA1226.1, 2009.

Seethala, C. and Horvath, A.: Global assessment of AMSR$\mathrm{E}$ and MODIS cloud liquid water path retrievals in warm oceanic clouds, J. Geophys. Res., 115, D13202, doi:10.1029/2009JD012662, 2010.

Stammes, P.: Spectral radiance modeling in the UV-Visible range, in: IRS 2000: Current Problems in Atmospheric Radiation, edited by: Smith, W. L. and Timofeyev, Y. M., A. Deepak Publ., Hampton, Va., 385-388, 2001.

Stengel, M., Kniffka, A., Meirink, J. F., Lockhoff, M., Tan, J., and Hollmann, R.: CLAAS: the CM SAF cloud property dataset using SEVIRI, Atmos. Chem. Phys. Discuss., 13, 26451-26487, doi:10.5194/acpd-13-26451-2013, 2013.

Stephens, G. L.: Radiation profiles in extended water clouds: II. Parameterization schemes, J. Atmos. Sci., 35, 2123-2132, 1978.
Stubenrauch, C., Kinne, S., and the GEWEX Cloud Assessment Team: Assessment of global cloud climatologies, GEWEX WCRP Global Energy and Water Cycle Experiment News, 19, 6-7, 2009.

Turner, D. D., Vogelmann, A. M., Austin, R. T., Barnard, J. C., Cady-Pereira, K., Chiu, J. C., Clough, S. A., Flynn, C., Khaiyer, M. M., Liljegren, J., Johnson, K., Lin, B., Long, C., Marshak, A., Matrosov, S. Y., McFarlane, S. A., Miller, M., Min, Q., Minnis, F., O'Hirok, W., Wang, Z., and Wiscombe, W.: Thin liquid water clouds: their importance and our challenge, B. Am. Meteorol. Soc., 88, 177-190, doi:10.1175/BAMS-88-2-177, 2007.

Varnái, T. and Davies, R.: Effects of cloud heterogeneities on shortwave radiation: comparison of cloud-top variability and internal heterogeneity, J. Atmos. Sci., 56, 4206-4224, doi:10.1175/15200469(1999)056<4206:EOCHOS>2.0.CO;2, 1999.

Varnái, T. and Marshak, A.: View angle dependence of cloud optical thicknesses retrieved by Moderate Resolution Imaging Spectroradiometer (MODIS), J. Geophys. Res., 112, D06203, doi:10.1029/2005JD006912, 2007.

Venema, V., Meyer, S., Gimeno García, S., Kniffka, A., Simmer, C., Crewell, S., Loehnert, U., Trautmann, T., and Macke, A.: Surrogate cloud fields generated with the Iterative Amplitude Adapted Fourier Transform algorithm, Tellus, 58A, 104-120, 2006.

Williams, K. D. and Webb, M. J.: A quantitative performance assessment of cloud regimes in climate models, Clim. Dynam., 33, 141-157, doi:10.1007/s00382-008-0443-1, 2009.

Wood, R. and Hartmann, D. L.: Spatial variability of liquid water path in marine low cloud: the importance of mesoscale cellular convection, J. Climate, 19, 1748-1764, 2006.

Wood, R., Bretherton, C. S., and Hartmann, D. L.: Diurnal cycle of liquid water path over the subtropical and tropical oceans, Geophys. Res. Lett., 29, 2092, doi:10.1029/2002GL015371, 2002. 